\title{
Therapeutic alliance and different treatment formats when delivering internet-based CBT for depression
}

\author{
Kristofer Vernmark
}

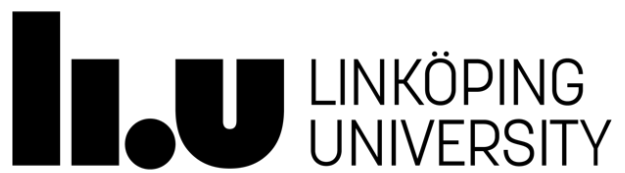

Linköping Studies in Arts and Science No. 725

Linköping Studies in Behavioural Science No. 201

Faculty of Arts and Sciences

Linköping 2017 
Linköping Studies in Arts and Science $\cdot$ No.725

Linköping Studies in Behavioural Science No. 201

At the Faculty of Arts and Sciences at Linköping University, research and doctoral studies are carried out within broad problem areas. Research is organized in interdisciplinary research environments and doctoral studies mainly in graduate schools. Jointly, they publish the series Linköping Studies in Arts and Science. This thesis comes from the Division of Psychology at the Department of Behavioural Sciences and Learning.

Distributed by:

Department of Behavioural Sciences and Learning

Linköping University

58183 Linköping, Sweden

Kristofer Vernmark

Therapeutic alliance and different treatment formats when delivering internetbased CBT for depression

Edition 1:1

ISBN 978-91-7685-436-5

ISSN 0282-9800

ISSN 1654-2029

(C) Kristofer Vernmark

Department of Behavioural Sciences and Learning, 2017

Cover by: Hambeck

Printed by: LiU-tryck, Linköping 2017 
Något slag för mycket ryckte i mitt bröst idag.

Någon sa att det beror på att jag ej mår bra.

Tänk om jag e sjuk?

Tänk om det bara var du?

Rymden e för stor, rymma e för långt.

Jorden e för liten, ingen som förstår.

Lyssnar jag i lurar på en viss låt, får jag nästan ta och skylla mig själv.

För jag är tagen men vet inte av vad

- Thibo Girardon 



\section{Acknowledgements}

Vi börjar med det viktigaste. När tillfället nu ges vill jag passa på att få med alla er som hjälpt mig att göra den här avhandlingen möjlig eller på andra sätt påverkat mitt liv till det bättre.

Ett stort tack skulle jag vilja rikta till...

Gerhard Andersson för att du öppnade dörren till forskarvärlden för mig redan som psykologstudent och sedan gav mig chansen att hoppa på som doktorand med dig som handledare. Tack för din stora tillit, dina uppmuntrande ord, förmåga till snabba beslut, enorma kompetens och ditt sällskap på Almedalen 2017 (du vann stort på kändisbingot...). Men din största insats var när du bjöd in Karolina till det där KLARA-mötet $\mathrm{i}$ grupprummet på biblioteket våren 2005. Det förändrade mitt liv.

Per Carlbring för din roll som biträdande handledare och den pålitliga samarbetspartnern du varit från KLARA tiden och framåt, i avhandlingens studier och andra forskningsprojekt. Tack för värdefull input på kappan under pressat tidsschema.

Alla forskarkollegor på Linköpings Universitet, och andra ställen, för trevliga möten, konferenser ihop och luncher på Blåmesen. Kristin Silfvernagel för ovärderlig hjälp under doktorandtiden. Utan din generositet och ditt stöd hade livet på Universitetet varit dubbelt så krångligt. Du har alltid tagit dig tid att hjälpa och haft stenkoll på allt det praktiska. George Vlaescu för en ny vänskap, mängder av fotbollsprat som bara du ville lyssna på och allt du fixat i E-COMPARED som gjort livet lättare för mig. Hugo Hesser för din hjälp med statistiken i den andra alliansartikeln. Med din hjälp förstod jag nästan vad jag höll på med. Kristoffer "två f" Månsson för att jag fick prata om Beck och göra en playlist utan att du himlade med ögonen. Naira Topooco för att du styrt oss genom E-COMPARED på ett fantastiskt fint sätt och för en alpvistelse som jag aldrig kommer glömma. Hoa Ly för ditt sällskap och för att du inspirerar i sättet du tänker och gör. Ali Sarkohi för din värme, din stående pingisinbjudan och din hjälp med intervjuerna i KLARA-studien. Matilda Berg för din härliga energi. Robert Persson Asplund för diskussioner om IKBT utanför universitetets portar, 
samt Jesper Dagöö, Peter Molander, Elisabeth Ingo, Stefan Blomberg, och alla andra på avdelningen för psykologi för forskarfikor och pratstunderna vid sofforna. Speciellt tack till Rickard Östergren för stödet när det blåste snålt under studietiden, alla diskussioner om behaviorism och din ofiltrerade syn på världen.

Tack till Britt-Marie Alfredsson för koll på allt kring kurser och avhandling, samt Ellinor Sellgren och även alla kursansvariga och föreläsare som gjort studierna som doktorand givande.

Maria Jannert för att du är du. Snabb i tanke och handling, klok och inspirerande. Jag minns fortfarande med glädje bilresan med dig till smärtföreläsningen i Örebro som nybliven psykolog.

Håkan Wisung för att du var en fantastisk handledare som ledde in mig på den behavioristiska vägen och stöttade mig i ambitionen att skapa något eget för Psykologpartners räkning.

Elin Sjöberg för samarbetet i utvecklingen av Depressionshjälpen. Du är den bästa arbetsboksansvariga personen jag träffat. Mikael Emtinger för din hjälp att skapa en grund till något större. Dina tankar, idéer och färdigheter gjorde att vi hamnade på rätt väg. Sara Isling för den fina skådespelarinsatsen, och Tommy Hedin för hjälpen att skapa filmerna i programmet.

Janne Lenndin för arbetet ihop med KLARA och fiskbullarna med rivna morötter i ditt kök. Först efteråt förstod jag vad det måste ha inneburit att ha småbarn, gå kurser, genomföra en stor RCT och skriva x-jobb samtidigt...

Mina psykologstudentvänner och framför allt alla som var del av KLARAstudien, Jonas Bjärehed, Mattias Carlsson, Jörgen Öberg och Johan Karlsson, det var fina tider som jag alltid kommer ha med mig.

Fredrik Holländare för att du tog dig tid att vara halvtidsgranskare och gav värdefull input, samt ditt fina arbete med DAVID-materialet ihop med Jan Bergström. Ni gjorde livet enkelt för oss som tog vid därefter. 
Lise Bergman Nordgren för rappa konversationer och granskningen vid slutseminariet. Du gjorde mig ordentligt förberedd för slutstriden.

Alla svenska medförfattare Björn Paxling, Maria Wiwe, Christina Bertholds Felix, Lisa Lundborg, Tomas Furmark, Malin Hägglund, Anne Luthström, Asa Kadowaki, Thomas Eriksson, Liisa Luuk och Lisa Backlund.

STELLA-gänget för hjälp med uppföljningsintervjuerna i KLARA-studie och författarna till studierna som bidrog med data till Paper II, ni som inte redan nämnts är Jonas Almlöv och Elisabeth Breitholtz.

Thanks to my international co-authors Pim Cuijpers, Thomas Berger and Heleen Riper.

Thanks to my opponent professor Ed Watkins. Treat me gently...

Thanks to professor Horvath, professor Hatcher and Fredrik Falkenström for your valuable input on the Working Alliance Inventory in Study IV.

Thanks to the E-COMPARED consortium for providing me with the opportunity to be a part of a large and important research project that will affect how we deliver internet-based interventions in regular health care.

Deltagarna i alla studier som gjort denna avhandling möjlig. Jag hoppas vi även gjorde skillnad i era liv.

Min vän och kollega Mats Dahlin som med varsam hand guidade psykologstudenterna i Umeå och gav värdefull input på avhandlingen. Samtal med dig är mumma för sinnet. Nu tycker storebror att det är din tur att ta över stafettpinnen, du behöver en till titel!

Fredrik Gunnarsson, Magnus Stalby, Tomas Rohal, Alberto Santi, Sara Hillbom, Therese Andersson, Marielle Ryberg, Jenny Curtsdotter och alla ni andra vänner och kollegor på mitt andra hem, Psykologpartners. Speciellt tack till digitalarna David Brohede, Ella Radvogin, Jenny Katalinic och Johan Edbacken för att det vi gör ihop för alltid kommer förändra synen på psykologer och psykologisk behandling. 
Thanks to Hambeck for creating an incredible cover of this thesis, helping me to pay tribute to the greatest musician and artist of all time - Beck Hansen

Anna, Åsa, Stefan, Karin, Ulrica, Ann-Britt och Claes för alla middagar, fester, födelsedagar, högtider och andra tillfällen vi spenderat tid ihop. Jag ser fram emot alla fina stunder vi har framför oss.

Gaëlle, Mattias, Cedric, Clara och Charlie. Hur skulle vi klara oss utan er som grannar.

Daniel, Kim och Liv, för alla middagar och vardagsstunder ihop, samt vägen genom det obegripligt svåra, som svetsat oss samman med er. Bitte, du är saknad.

Vår andra familj, familjen Sandvall, för att ni är en viktig del av vårt liv och att det känns som ni tillhör oss på något sätt...

Mina vänner Carl, Calle, Erik, Mattias, Magnus $P$ och Magnus S. Jag kommer aldrig släppa er.

Morfar för att du genom andras berättelser om dig inspirerat till att göra det som du en gång gjorde.

Farmor för din livsglädje, otroliga minne och stunderna i din säng framför Vita Lögner.

Mormor och Lina för att jag saknar er så mycket.

Mamma och pappa för att ni finns, ert stöd och att ni är världens bästa farmor och farfar. Med er som förebilder blev akademin ett självklart val i livet.

Min älskade bror, vad skulle jag göra utan dig. Du är den finaste person jag känner. Ju mer tid jag får med dig och din fantastiska familj (Mican, Melissa och William), desto lyckligare blir jag. Nästa anhalt - Florida. 
Min älskade familj, Karolina, Joel, Liam och Elly. Ni går före allt. Livet före er minns jag knappt. Forskning är bara ett sätt att få timmarna att gå i väntan på att träffa er.

PS. Tänk dig alla avhandlingar som skrivits i hela världen och att man skulle behöva läsa allihop på en dag, så jobbigt som det skulle vara, så mycket älskar jag dig Karolina Vernmark... 



\begin{abstract}
Depression is a debilitating disorder that affects a large part of the adult population every year. Yet there is still a lack of access to effective care for people in need. Cognitive behaviour therapy (CBT) is an evidence-based method for treating depression that is usually provided in a face-to-face setting. With new technological solutions and internet-access growing around the world, there is an opportunity to use these digital tools to provide effective treatment to a wider population. Research has shown that internetbased interventions can be effective in the treatment of depression, but there is still a lack of knowledge concerning which formats of delivery that can be used and how treatment can be delivered in the best possible way. Treating depression online means less face-to-face contact between therapist and patient, and instead using other channels for communicating such as secure email. For many clinical psychologists, psychotherapists and psychotherapy researchers the foundation of effective treatment lies in the therapeutic alliance created through the face-to-face meeting between therapist and patient. An interesting question is if alliance is of equal importance when providing treatment over the Internet, or when parts of the treatment are provided in that way.
\end{abstract}

The overall aim of this thesis was to examine the effects of different treatment formats (email therapy, guided self-help, and blended treatment) in internet-based CBT for depression and to further examine the role of therapeutic alliance in these treatment modalities. Participants in all studies fulfilled the criteria for major depression. In Study I, a CBT-based email therapy manual for adults with depression and an existing internet-based self-help program, were both tested against a waiting list control group in a randomized controlled trial. Results showed large effects on depressive symptoms for email therapy and moderate effects for the guided self-help group compared to the control group, although clinically relevant change was comparable between both treatment conditions. Effects were maintained at 6-months and there were no significant differences between treatment groups. Study II was based on data from the first study and examined the role of alliance in these two treatment modalities. Specifically, level of alliance and its ability to predict outcome. Data from two other 
studies on social anxiety and generalized anxiety was also included in this study. Patient-rated alliance was high for all three samples, but could not predict outcome. Study III compared a therapist guided internet-based treatment program, based on behavioural activation (BA) with components of acceptance and commitment therapy (ACT), to a wait list control group in a randomized controlled trial. At post-treatment, large and significant positive effects on depressive symptoms were seen, and there was no difference in change scores when controlling for the presence of comorbid dysthymia. Effects were maintained at 3-month follow up. Only a relatively small proportion of the participants $(25 \%)$ fulfilled the criteria for clinically relevant change. In Study IV the role of alliance in blended treatment (a mix between face-to-face and guided self-help treatment online) for adults with depression was examined. Specifically, the role of patient- and therapist rated working alliance when predicting change rate in depression during treatment was investigated. Results showed that therapist-rated alliance at week four could predict change scores in depression during treatment, whereas patient-rated alliance could not. Therapeutic alliance rated by patients and therapists was high and similar to what has been seen in earlier face-to-face and internet-based treatment studies.

This thesis includes the first randomized controlled study on CBT-based email therapy and also the first trial of internet-based behavioural activation with ACT-components for adult depression. Findings show that both formats can be effective methods for treating depression. Also, alliance ratings were high suggesting that it is possible to create a positive working alliance between therapist and patient in internet-based treatment. The role of alliance as a predictor of outcome seems to be different than in face-toface treatment, as patient-rated alliance was not significantly correlated with outcome in any of these studies. There is a continued need for more research on the role of different treatment formats and the role of alliance in internetbased treatments. Findings in this thesis are preliminary and must be seen in the wider context of research on outcome and alliance in psychotherapy.

Keywords: depression, internet-based treatment, cognitive behavioural therapy, therapeutic alliance, email therapy 


\section{Empirical studies}

I. Vernmark K., Lenndin J., Bjärehed J., Carlsson M., Karlsson J., Öberg J., Carlbring, P., Eriksson, T., \& Andersson, G. (2010). Internet administered guided self-help versus individualized e-mail therapy: A randomized trial of two versions of CBT for major depression. Behaviour Research and Therapy, 48, 368376.

II. Andersson, G., Paxling, B., Wiwe, M., Vernmark, K., Bertholds Felix, C., Lundborg, L., Furmark, T., Cuijpers, P., \& Carlbring, P. (2012). Therapeutic alliance in guided Internet-delivered cognitive behavioral treatment of depression, generalized anxiety disorder and social anxiety disorder. Behaviour Research and Therapy, 50, 544-550.

III. Carlbring, P., Hägglund, M., Luthström, A., Dahlin, M., Kadowaki, A., Vernmark, K. \& Andersson, G. (2013). Internetbased behavioral activation and acceptance-based treatment for depression: a randomized controlled trial. Journal of Affective Disorders, 148, 331-337.

IV. Vernmark, K., Hesser, H., Topooco, N., Berger, T., Riper, H., LuUk, L., Backlund, L., Carlbring, P., \& Andersson, G. (2017). Working alliance as a predictor of change in depression during blended cognitive behavior therapy. Manuscript submitted for publication. 


\section{Abbreviations}

\begin{tabular}{|c|c|}
\hline ANCOVA & Analysis of covariance \\
\hline ANOVA & Analysis of variance \\
\hline ACT & Acceptance and Commitment Therapy \\
\hline AMT & Autobiographical Memory Test \\
\hline BAI & Beck Anxiety Inventory \\
\hline BCBT & Blended Cognitive Behaviour Therapy \\
\hline BDI & Beck Depression Inventory \\
\hline CBT & Cognitive Behaviour Therapy \\
\hline CGI & Clinical Global Improvement \\
\hline DSM & $\begin{array}{l}\text { Diagnostic and Statistical Manual of Mental } \\
\text { Disorders }\end{array}$ \\
\hline Face-to-face & $\begin{array}{l}\text { A description of the traditional setting for } \\
\text { psychotherapy, where the therapist and patient } \\
\text { meet in person }\end{array}$ \\
\hline FTT & Future Thinking Task \\
\hline GAD & Generalized Anxiety Disorder \\
\hline ICD & $\begin{array}{l}\text { International Classification of Diseases and Related } \\
\text { Health Problems }\end{array}$ \\
\hline LSAS-SR & Liebowitz Social Anxiety Scale - Self report \\
\hline MAR & Missing At Random \\
\hline MDD & Major Depressive Disorder \\
\hline ICBT & Internet-based Cognitive Behaviour Therapy \\
\hline MADRS & Montgomery Åsberg Depression Rating Scale \\
\hline MINI & Mini International Neuropsychiatric Interview \\
\hline PHQ-9 & Patient Health Questionnaire \\
\hline PSWQ & Penn State Worry Questionnaire \\
\hline PTSD & Post-traumatic Stress Disorder \\
\hline QOLI & Quality of Life Inventory \\
\hline $\mathrm{RCT}$ & Randomized Controlled Trial \\
\hline REML & Restricted Maximum Likelihood \\
\hline SPSS & Statistical Package for Social Sciences \\
\hline SAD & Social Anxiety Disorder \\
\hline SCID & Structured Clinical Interview for DSM \\
\hline TAU & Treatment As Usual \\
\hline WAI & Working Alliance Inventory \\
\hline
\end{tabular}




\section{Table of contents}

$\begin{array}{ll}\text { INTRODUCTION } & 1\end{array}$

DEPRESSION 2

$\begin{array}{ll}\text { Measuring depression } & \mathbf{3}\end{array}$

$\begin{array}{lr}\text { Prevalence and comorbidity } & 5\end{array}$

$\begin{array}{ll}\text { Cognitive behaviour therapy for depression } & 6\end{array}$

Versions of CBT and specific treatment content $\quad 8$

$\begin{array}{lr}\text { INTERNET-BASED TREATMENT } & 14\end{array}$

Formats of delivery $\quad 14$

$\begin{array}{ll}\text { Internet-based CBT } & 17\end{array}$

$\begin{array}{ll}\text { Internet-based CBT for depression } & 19\end{array}$

$\begin{array}{ll}\text { Specific treatment programs } & 21\end{array}$

Blended treatment $\quad 22$

Email therapy $\quad 24$

The role of therapist support $\quad 25$

$\begin{array}{lr}\text { THERAPEUTIC ALLIANCE } & 28\end{array}$

$\begin{array}{lr}\text { Prediction of outcome } & 29\end{array}$

$\begin{array}{ll}\text { Therapeutic alliance in internet-based treatment } & \mathbf{3 0}\end{array}$

Measuring the therapeutic alliance 32

Working Alliance Inventory $\quad 33$

Versions used in this thesis $\quad 35$

$\begin{array}{ll}\text { OVERALL AIM } & 36\end{array}$

$\begin{array}{ll}\text { EMPIRICAL STUDIES } & 37\end{array}$

$\begin{array}{ll}\text { PAPER I } & 37\end{array}$

$\begin{array}{lr}\text { Aim } & 37\end{array}$ 
PAPER II

Aim

Methods and results

Discussion

PAPER III

Aim 50

Methods 50

Results and discussion

52

PAPER IV

Aim 55

Methods 55

Results and discussion

GENERAL DISCUSSION

Main findings

Limitations 64

Conclusions and future directions 65 


\section{Introduction}

Depression is a debilitating disorder that continues to affect millions of people every year and is the leading cause of disability worldwide. Its effects on everyday life can be devastating and may lead to increased passivity and patterns of avoidance from occupational routines, social interactions and other important daily activities. Yet, it seems that we struggle with the mission to provide effective treatment to all those people in need of help. Computers, Internet and new landmarks in technology continue to provide new options when delivering interventions in the health care sector. In the medical field, it has been an ongoing technological integration for many years, changing the way we look at, deliver and experience medicine. In the domain of psychology, the wheels have been turning a bit slower. With the rise of internet-based interventions, the opportunity to provide effective treatment at a distance has become a reality and made the psychology community wake up and take on the challenge. There is however a need for further studies, as internet-based treatment can be delivered in many different formats. The amount of therapist contact provided could vary considerably, as well as the extent to which self-help material is used. Moreover, the inclusion of interactive elements and the theoretical content of the treatment provided have the possibility to influence treatment.

However, there are obstacles. Philosophical premises, theoretical conceptions and methodological skills have changed over the years, but usually not the setting - the therapist office. Many consider this face-to-face meeting to be the foundation for creating a therapeutic alliance between therapist and patient, and therefore making it crucial for effective treatment. So, can alliance be fostered and work the same way when providing treatment over the Internet, or when parts of the treatment is provided in that way? This thesis aims to explore the use of different treatment formats and the role of therapeutic alliance when delivering internet-based treatment for adult depression. Hopefully the included studies can be helpful in the understanding of how to best use internet-based treatment and what part alliance plays when using this format. If so, I am proud to have contributed a small step on the way to something much bigger. 


\section{Depression}

Depression, also called major depressive disorder (MDD; Kessler et al., 2003), is a common mental disorder that is associated with large debilitating effects and functional impairments (Alonso, Lépine, ESEMeD/MHEDEA 2000 Scientific Committee, 2007; Johansson, Carlbring, Heedman, Paxling, $\&$ Andersson, 2013b; Murray et al., 2012). In addition to human suffering, the costs for society are high, especially in terms of productivity loss. In Sweden between the year of 1997 and 2005 there was a dramatic increase in sick leave for depression (Sobocki, Lekander, Borgström, Ström, \& Runeson, 2007) and recent reports have stated that psychiatric conditions as a reason for sick leave has increased compared to others conditions. As if this was not troubling enough, it seems that more than half of those individuals struggling with depression choose not to seek health care services for their problems (Ebmeier, Donaghey, \& Steele, 2006). And of those that seek help, less than half get adequate treatment (Kessler et al., 2003). Altogether, there is an urgent need for developing and providing effective and scalable treatment options that can help relieve suffering for a large number of individuals struggling with a disorder that we know there is effective help for.

There are different psychological models for depression. A common conceptualization from a behaviouristic perspective is the cycle of depression (Martell, Addis, \& Jacobson, 2001). Life changing events, be it large ones or the additive effect of many small ones, leads to decreased positive reinforcement and increased contact with punishing consequences (aversive stimuli). Activities that are negatively reinforced increases, such as avoidance behaviours, and secondary problems as inactivity and rumination increases. This in turn leads to feelings of hopelessness, guilt, sadness, increased fatigue and depressed mood. Which leads to an even narrower behavioural repertoire with increased avoidance behaviours and rumination. From a cognitive perspective depression is connected to dysfunctional negative views of oneself, the world and the future, called the cognitive triad (Beck, 1967). These views are present in negative automatic thinking, which is a central component in depression. Also, negative selfschemata, often originating from childhood experiences, leads to negative 
interpretations of present situations. A final theme is the distortion of thought processes. These illogical thought patterns can be self-defeating and cause symptoms associated with depression. Recent developments of the cognitive model have also included the concept of cognitive reactivity, meaning that negative attitudes towards oneself can vary in response to daily events (Beck, 2008).

\section{Measuring depression}

Depression is classified as an affective disorder and is characterized by psychological, behavioural and physiological symptoms. There are two major classification systems, the Diagnostic and Statistical Manual of Mental Disorders (DSM-IV-TR; American Psychiatric Association, 2000) and the International Classification of Diseases (ICD-10; World Health Organization, 1992). These classification systems are largely compatible, although not identical, regarding the classification of depression (Saito et al., 2010). Even though ICD-10 is the standard for Swedish health care, DSM is more frequently applied in research on treatment for depression.

DSM criteria for depression are conceptualized as depressed mood or a loss of interest or pleasure in daily activities every day for more than two weeks. It represents a change from a person's baseline mood and symptoms have to be present nearly every day. These symptoms should cause impaired social, occupational and/or educational functioning. Moreover, physiological effects of a substance or a general medical condition cannot better explain the symptoms. At least five of the nine symptoms, including one or both of the cardinal symptoms depressed mood or decreased interest or pleasure, have to be fulfilled to diagnose MDD. The other symptoms are significant change in weight or appetite, insomnia or hypersomnia, psychomotor agitation or retardation, loss of energy, feelings of worthlessness or/and excessive guilt, diminished ability to concentrate and lastly recurrent thoughts of death, suicidal ideation, plans for suicide or actual attempts.

Although a new updated version of DSM has been developed (DSM-5; (American Psychiatric Association, 2013), the classification used in all included studies in this thesis was based on DSM-IV. The diagnostic criteria 
for depression are mainly the same between versions, with the exception of the removal of bereavement as exclusion criteria in diagnosing MDD. There is also increased guidance regarding suicidality and clarifications regarding bipolarity (Rodríguez-Testal, Senín-Calderón, \& Perona-Garcelán, 2014).

Using structured or semi-structured instruments to diagnose MDD increases diagnostic sensitivity and specificity compared to clinical judgment. In a large review of diagnostic instruments (Statens beredning för medicinsk utvärdering [SBU], 2012), only two interview manuals were considered to have enough scientific evidence regarding both sensitivity and specificity Structured Clinical Interview for DSM-IV Axis-I Disorders (SCID-I; First, Spitzer, Williams, \& Gibbon, 1997) and Mini International Neuropsychiatric Interview (M.I.N.I.; Sheehan et al., 1998).

A common way for measuring level of depression is through the use of questionnaires. Beck Depression Inventory (BDI; Beck, Ward, Mendelson, Mock, \& Erbaugh, 1961) is one of the most frequently used questionnaires for measuring symptoms of depression in psychotherapy research studies and has good psychometric properties (Beck, Steer, \& Garbin, 1988b). The revised version, Beck Depression Inventory-II (BDI-II; Beck, Steer, \& Brown, 1996), has been shown to have similar psychometric properties (Titov et al., 2011). Patient Health Questionnaire (PHQ-9; Kroenke, Spitzer, \& Williams, 2001) is a widely used instrument that has good internal consistency, test-retest reliability and external validity. Montgomery Asberg Depression Rating Scale-Self Rated (MADRS-S; Svanborg \& Åsberg, 1994) was developed as an easily administered rating scale to be used in primary care and has comparable reliability with BDI (Svanborg \& Åsberg, 2001) and BDI-II (Wikberg et al., 2015). Although different in format, there is research to support the notion that these questionnaires seem to correlate substantially and that they are all useful when measuring depression. All of the above questionnaires have been shown to have similar psychometric qualities when delivered online (Carlbring et al., 2007; Holländare, Andersson, \& Engström, 2010). 


\section{Prevalence and comorbidity}

Epidemiological studies from Western Europe, North America and Australia show similar rates of major depression in the general adult population, between $3-7 \%$ for 12 -month prevalence (Andrews, Henderson, \& Hall, 2001; Ferrari et al., 2013; Kessler, Chiu, Demler, Merikangas, \& Walters, 2005b). Lifetime prevalence is naturally higher with studies showing rates between 13-17\% (Alonso et al., 2007; Kessler, Berglund, Demler, Jin, Merikangas, \& Walters, 2005a). In Sweden the prevalence seems to be approximately the same, as a recent survey in the general population found a $5.2 \%$ point prevalence for major depression (Johansson, Carlbring, Heedman, Paxling, \& Andersson, 2013b). Some of the risk factors that are commonly associated with fulfilling criteria for MDD are gender and marital status, with an increased risk for women and unmarried individuals (Andrade et al., 2003).

Comorbidity is common among patients with mental health disorders (Kessler, Chiu, Demler, Merikangas, \& Walters, 2005b). Results from an US-comorbidity survey showed that $57.5 \%$ of those who fulfilled the criteria for major depression also met criteria for at least one anxiety disorder (Kessler, Merikangas, \& Wang, 2007) and similar results have been found in other surveys conducted in Sweden (Johansson, Carlbring, Heedman, Paxling, \& Andersson, 2013b). It adds to the burden of disease for depressed individuals and is associated with higher symptom severity (Kessler et al., 2003). Highest level of disability can be seen in individuals meeting criteria for comorbid disorders, and level of impairment seems to increase with number of comorbid conditions (Alonso et al., 2004). A common comorbid diagnose is dysthymia (Persistent Depressive Disorder in DSM-5), defined as a depressed mood for most of the day, for more days than not, during at least a two-year period. Comorbidity for this diagnose with MDD has been shown to be as high as $53 \%$ in certain surveys (Alonso et al., 2007).

The course of depression is often described as individuals responding (to treatment), reaching remission, relapsing, recovering and having a recurrence of depressive episodes (Hollon et al., 2002). A response to 
treatment would a positive effect, meaning symptom improvement, whereas remission would be the full normalisation (few or no symptoms associated with depression). A return of symptoms within six to nine months would be considered a relapse, and those that remain in remission during the same treatment period would be considered recovered. If patients experience an increase in symptoms after being defined as recovered, this would be defined as a recurrence of a depressive episode. Depression can be cyclic with spontaneous improvement without treatment, which also has been observed in waiting list conditions in psychotherapy research (Rutherford, Mori, Sneed, Pimontel, \& Roose, 2012).

\section{Cognitive behaviour therapy for depression}

Treatment for depression has been delivered in a wide variety of ways, including e.g. antidepressant medication (Bauer, Severus, Möller, Young, WFSBP Task Force on Unipolar Depressive Disorders, 2017), electro convulsive therapy (Pagnin, de Queiroz, Pini, \& Cassano, 2004), physical activity (Nyström, Neely, Hassmén, \& Carlbring, 2015) and psychotherapy (Cuijpers, 2016). Up until 2013, more than 400 randomized trials on psychotherapy for adult depression had been conducted (Cuijpers, 2015). These trials have shown that several different psychotherapies, such as cognitive behaviour therapy, interpersonal psychotherapy, behavioural activation, problem solving therapy and psychodynamic psychotherapy are effective when treating depression (Barth et al., 2013; Cuijpers, 2015; Hollon \& Ponniah, 2010). However, the question if psychotherapies are equally effective when treating depression is difficult to answer due to the lack of power in studies comparing treatments with each other (Cuijpers, 2016).

Cognitive behaviour therapy (CBT) is to this day the most researched psychotherapy method for depression and a recent meta-analytic update found 63 randomized controlled studies that compared CBT to a control group when treating major depression (Cuijpers, Cristea, Karyotaki, Reijnders, \& Huibers, 2016a). The overall effect size for measurements of depression in these studies was moderate to large (Hedges' $g=0.75$ ), 
favouring CBT. Effect sizes are commonly interpreted using the definition of a small effect as 0.2 , medium effect as 0.5 and a large effect as 0.8 and above (Cohen, 1988). Studies on CBT versus waiting list showed significantly larger effect sizes compared to studies using care as usual or placebo control groups as the comparison (Cuijpers et al., 2016a).

There is enough evidence to conclude that psychological treatments are effective for mild and moderate depression. When it comes to more severe depression there is an ongoing debate whether CBT and other psychotherapies are effective (Hollon et al., 2002). Driessen and fellow researchers analysed data from 132 studies and concluded that pre-treatment severity does not moderate the effects of treatment (Driessen, Cuijpers, Hollon, \& Dekker, 2010). In fact, there was actually a tendency for CBT to be more effective for high-severity patients compared to low-severity patients. Another meta-analysis published the same year included 16 randomized controlled studies that examined the effects of psychotherapy and pharmacotherapy on chronic depression and dysthymia (Cuijpers, van Straten, Schuurmans, Van Oppen, Hollon, \& Andersson, 2010b). Psychotherapy had a significantly smaller effect than pharmacotherapy, but the analysis showed that this difference could be attributed to the presence of dysthymia, making this diagnosis a complicating circumstance when delivering CBT for depression.

Most studies have defined successful treatment of depression by means of statistical significance, but researchers have called for the use of clinical significance as a more reliable measure of meaningful individual change (Nasiakos, Cribbie, \& Arpin-Cribbie, 2010). The problem with clinical significance so far has been that the definitions, statistical methods and instruments used for measuring have varied greatly, although specific methods as the Jacobson method has been put forward as preferable methods calculating clinical significance (Bauer, Lambert, \& Nielsen, 2004; Jacobson \& Truax, 1991). The balance between using definitions that are easily understood (such as the absence of a MDD-diagnose after treatment or a score below certain cut-off on a questionnaire) has to be contrasted with the stricter definitions, such as high-end-state functioning. 
The significant negative effects of depression on quality of life have been seen in surveys (Johansson, Carlbring, Heedman, Paxling, \& Andersson, 2013b). A meta-analysis examining the effects on quality of life in treatments for depression showed small to moderate effects on these measures (Kolovos, Kleiboer, \& Cuijpers, 2016). Positive changes in quality of life could not be fully explained by symptom improvement in depression during treatment and an interesting observation is that the out of the included sample, only nine of the 31 individual studies showed significant effects on quality of life. This indicates that even though there are positive effects on life quality after psychotherapy for depression in pooled data samples, these effects are often not seen in the separate studies.

\section{Versions of CBT and specific treatment content}

CBT has many different definitions. It is sometimes defined as a mix of cognitive and behavioural interventions and sometimes as an umbrella term for most empirically validated methods for a certain psychiatric condition. Classic CBT for depression has its roots in the work on cognitive therapy by Aaron Beck (Beck, 1963; 1964). It includes both cognitive and behavioural interventions and has been studied as a treatment method for depression since the 70's (Rush, Beck, Kovacs, \& Hollon, 1977). The CBT-program used in Paper I included the components seen in Table 1.

Table 1

Contents in the self-help program used in Paper I

\section{Module 1 - Introduction to CBT}

This module is an introduction to with focus on behavioural and cognitive aspects of the therapeutic method, including the connection between behaviours, thoughts and emotions. The concept of reinforcement is introduced. It also addresses common conceptions about CBT. 
Module 2 - Depression from a CBT-perspective

This module explains the cycle of depression and from a CBT-perspective. Different types of reinforcement are exemplified and the concept of negative and positive maintenance circles are introduced.

\section{Module 3-Behavioural activation, part 1}

This module introduces behavioural activation and the activation plan. Tools are given to measure level of activity and categorize activities as positively and negatively reinforced. Also, the connection between activity and mood is discussed. Strategies for increasing the probability of important activities are provided.

\section{Module 4 - Behavioural activation, part 2}

This module is a continuation of module three and contains further work with the activation plan, and explains how this work can lead to increased wellbeing. The concept of how activation creates motivation, instead of the opposite, is introduced. Exercises include specifying and planning rewards for performed activities.

\section{Module 5 - Cognitive restructuring}

This module is focused on the effect of thoughts on emotions and behaviours. The concept of automatic thoughts and cognitive restructuring is introduced. Strategies for cognitive restructuring are provided.

\section{Module 6a-Sleep strategies}

This module includes information about sleep and strategies for better sleep. Relaxation methods are provided and a sleep diary is introduced.

Module $6 b$-Sleep strategies (optional)

This optional module includes seven strategies for better sleep, called sleep hygiene. 
Module 7 - Relapse prevention, values and goals

This module is focused on repetition and continued progress. Working strategies from earlier modules are summarized and a creating a relapse plan is part of the module. Information about the importance of values and goals for maintained wellbeing is addressed.

Modules used in Study IV were similar to those in Study I. Except from the fact that face-to-face sessions were included in the blended treatment, the main differences between the treatment programs were that goal setting was clearer earlier on, that a larger part was focused on cognitive restructuring and that there was no focus on sleep strategies in the program used in Study IV. The content of the email therapy was derived from the self-help program used in Paper I and included similar content, but delivered in a more individualized way. Therapists were provided a manual developed for the specific study. A difference compared to the self-help program was that email therapists were prompted to provide a functional analysis and case conceptualization for each specific participant in the beginning of treatment. The therapists were recommended to provide content in the same order as in the self-help program, but it was up to each therapist to individualize to each participant's specific needs.

Behavioural activation (BA) is a treatment method created by Jacobson and colleagues (Jacobson et al., 1996). It was suggested as a stand-alone treatment method after a component analysis treatment study comparing BA, BA with components targeting automatic thoughts, and the full CBTpackage. Results showed equal effects for all three treatments. This meant that removing the cognitive interventions from CBT, and only keeping behavioural activation techniques, did not affect the treatment results in a negative way. An expanded version of the BA-approach was tested in yet another study showing similar results (Dimidjian et al., 2006). This version included functional strategies for handling rumination, an increased focus on how to handle avoidance behaviours, and strategies for establishing regularized routines. Today, behavioural activation is a widely used treatment method for depression and research on this method has increased 
dramatically since the turn of the century (Dimidjian, Barrera, Martell, Muñoz, \& Lewinsohn, 2011). In a meta-analysis including 26 randomized controlled trials of behavioural activation superior effects were found compared to waiting list control conditions and treatment as usual (Ekers et al., 2014).

A more functional approach to thoughts and feelings differentiate BA from earlier activation strategies used for treating depression (Lewinsohn, Muñoz, Youngren, \& Zeiss, 1986), and the view of experiential avoidance is shared with functional contextualistic therapies such as Acceptance and commitment therapy (ACT; Hayes, Strosahl, \& Wilson, 2012). The addition of ACT-based strategies to BA, such as working with values, mindfulness and acceptance, has been tested in a pilot study using a group setting (Houghton, Curran, \& Saxon, 2008). The results were promising and more than one third of the participants experienced clinically relevant improvement. The inclusion of these components could potentially increase effects on comorbid psychological problems, as ACT interventions are transdiagnostic in their nature. In Depressionshjälpen, the treatment program used in Paper III, ACT-strategies were added to complement behavioural activation strategies (see Table 2). The author of this thesis together with another psychologist, Elin Sjöberg, developed the content of this self-help program.

Table 2

Contents in the self-help program used in Study III

Module 1-About depression

This module included a rationale and psychoeducation regarding depression, cognitive behaviour therapy and internet-based treatment. Assignments in the workbook included registering factors that maintain depressive symptoms and strategies used up until now to handle depression. Also, an activity chart is presented in the workbook, covering activity and the connection to depressed mood. 


\section{Module 2 - Activity and mood}

This module dealt with avoidance behaviours, and behaviours with a negative influence on mood. Assignments in the workbook included registrations of daily activities and avoidance behaviours.

\section{Module 3 - The role of reinforcement}

This module included psychoeducation regarding the function of activities and the role of positive reinforcement. Activities associated with pleasure and mastery are introduced, and also those activities that are neither associated with pleasure nor mastery. Assignments in the workbook included registering activities and defining rewards.

\section{Module 4-How to make a difference in your daily life}

This module focused on behavioural change and was based on the work done in module three to plan and perform activities. Content includes specific suggestions on how to plan activities and how to reward these. The workbook contained material to schedule and monitor planned activities.

\section{Module 5 - Thoughts and emotions}

This module introduced the specific role of thoughts and emotions in depression. Functional strategies based on defusion, acceptance and mindfulness are provided. Regular practice using the CD with mindfulnessand acceptance exercises is prompted. The workbook is used to write down specific thoughts and feelings that are hard to cope with and reviewing how current strategies are working.

\section{Module 6-Repetition and continued practice}

This module includes repetition of the most important parts from previous modules. It also includes goal planning and scheduling of activities. Assignments in the workbook are summarizing how scheduling activities has worked and creating a plan for the next two weeks based on strategies that have worked so far. 


\section{Module 7 - Relapse prevention}

This module provides a summary of the whole treatment. Assignments in the workbook include evaluating efforts and achievements so far, specifying behavioural changes that have been made and creating a plan for maintaining treatment gains and relapse prevention. 


\section{Internet-based treatment}

Internet-based treatments have been an area of interest for researchers since the turn of the century. Providing treatment in a digital format over the Internet can help reach individuals suffering from depression and other psychiatric conditions in an extensive way, which face-to-face psychotherapy has been struggling to do given the number of people in the need of help. There are many advantages that come with using available technology (Emmelkamp et al., 2014). Among the benefits are the possibility to make psychological treatment scalable, to increase quality in interventions and to provide unique transparency for patients into their own treatment. From a researcher's perspective, technology could facilitate doing studies in a more efficient and specific manner with interesting possibilities up ahead, e.g. regarding component analysis in psychotherapy (Watkins et al., 2016). Sweden has been a major contributor to this area of research and in a recent overview on internet-based cognitive behaviour therapy (ICBT) for anxiety, all but five of 37 included studies were conducted by research groups in Sweden and Australia (Mewton, Smith, Rossouw, \& Andrews, 2014). One explanation for Sweden's prominent role could be that more than $90 \%$ of the Swedish population are Internet users and $82 \%$ use it daily (Internetstiftelsen i Sverige [IIS], 2016) making it a suitable channel to deliver interventions.

\section{Formats of delivery}

The history of using computers in psychological treatment can be traced back to early attempts by computer scientist Joseph Weizenbaum (Weizenbaum, 1966). His chatterbot program ELIZA aimed to mimic human conversation and was the first attempt to create a digital psychotherapeutic intervention. ELIZA used natural language processing and included a script that was supposed to mimic the conversational style of Carl Rogers, using open ended questions in an empathic manner (Helgadóttir, Menzies, Packman, \& O'Brian, 2009). The work of Weizenbaum had a major impact in the research on artificial intelligence but has up to date unfortunately had little impact on the area of psychological 
treatment and internet-based interventions. Instead, the story begins with books.

The growing popularity of self-help books in the 1960's, as well as the results in early research on self-help interventions, indicated that bibliotherapy could be an effective treatment option (Glasgow \& Rosen, 1978). Self-help can be defined as the patient receiving a standardized treatment package, which can guide the user to help him- or herself without major input from a therapist (Cuijpers, 1997). Compared to traditional psychotherapy, bibliotherapy has the possibility to empower patients to solve their problems on their own, create freedom to work in one's own pace in a home setting and minimize expenses associated with therapy (Marks, Cavanagh, \& Gega, 2007). Moreover, there is a possibility to reach those suffering but that are hesitant to seek out help because of stigma associated with psychiatric illness. In a meta-analysis including 14 studies on self-help (mainly bibliotherapy supported by a therapist), results showed that it was more effective than control conditions, Cohen's $d=.84$ (Boer, Wiersma, \& Van den Bosch, 2004). The positive effects were sustained at follow up, $d=.76$, and compared to other treatment conditions (mainly faceto-face CBT), self-help treatment was equally effective. There are actually quite a few reviews and meta-analyses supporting the notion that bibliotherapy is effective with moderate to large effects (Cuijpers, 1997; Gould \& Clum, 1993; Gregory, Schwer Canning, Lee, \& Wise, 2004). Taking the data into consideration it is interesting that bibliotherapy with the support of a therapist has not succeeded in being an integrated part of health care services usually provided. A survey on CBT-therapists in the United Kingdom showed that bibliotherapy was widely accepted with more than $88 \%$ using it in their practice, but that $99 \%$ used it as a supplement to faceto-face therapy (Keeley, Williams, \& Shapiro, 2002). It seems that the use of self-help materials has been more accepted as an addition to face-to-face therapy than as a stand-alone treatment with minimal therapist support.

With the rise of home computers in the 1980's, researchers turned their attention towards the use of computers in the delivery of psychological treatment. In the book Hands on help: computer aided psychotherapy (Marks et al., 2007), 175 published and unpublished trials on computer- 
aided psychotherapy was included and the authors state that this way of delivery has several distinct advantages compared to bibliotherapy. It provides greater interactivity and opportunities for individual tailoring, increases the speed of updating content in self-help programs and gives the possibility to provide treatment to more patients without higher costs (no printing costs). An interesting aspect is that the added effect of using other elements than text had been found in earlier research on self-help interventions. Gould and Clum stated in their meta-analysis that the combination of written material and video or audio was more effective than written material on its own (Gould \& Clum, 1993).

As Internet became available for a broader population in the 1990's, a crucial component was added. It made the dissemination of interventions easier, and the use of structured self-help provided online appeared to be an opportunity for providing a cost-effective treatment that could bridge geographical boundaries (Andersson \& Carlbring, 2003). Early treatment packages for depression online was based on, or inspired by, self-help books such as Control your depression (Lewinsohn et al., 1986) and Feeling Good (Burns, 1999) that had been proven effective in earlier research (Cuijpers, 1998; Scogin, Jamison, \& Davis, 1990). The similarities with bibliotherapy were obvious and participants were given the possibility to download material as PDF-files to print and read in paper format (Andersson et al., 2005). Internet-delivered treatment was defined as self-help books online with the addition of therapist contact through email or by telephone, in combination with certain interactive functions such as online registrations and discussion boards (Andersson et al., 2008). This way of delivering treatment was even called net biblioCBT by Marks and colleagues (Marks et al., 2007).

It was only natural that early internet-based treatment programs were based on CBT-methods. Relying on a structured format and with a history of treatment manuals for therapist, with the addition of structured homework material for patients, it can be said that CBT was better suited than other treatment formats for delivering self-help online. In a systematic review Hedman and colleagues found 103 studies on guided ICBT that reported 
clinical efficacy, making it the most widely studied internet-based therapy orientation (Hedman, Ljótsson, \& Lindefors, 2012).

The increasing research on different variations of internet-based interventions has led to a lack of common terminology (Proudfoot et al., 2011). Several attempts have been made to clarify and structure these different ways of delivery online. Barak, Klein and Proudfoot divided research into web-based interventions, online counselling and therapy, Internet-operated therapeutic software and other online activities (Barak, Klein, \& Proudfoot, 2009). The last category included different supplements to face-to-face therapy. Others have defined certain types of internet-based treatment more specifically, such as a therapist guided internet-delivered self-help (Andersson, 2009), or have made a distinction based on therapist contact and support during treatment dividing internet interventions into unguided self-help programs, guided self-help programs and internet-based psychotherapies (Berger, 2017, p. 512). Using the latter distinction, the different treatment modalities in this thesis would have been categorized as either internet-based guided self-help (the self-help programs in Paper I and III) or internet-based psychotherapy (email therapy in Paper I), whereas blended treatment would not have been included in any of these categories. Since different definitions exist, this thesis has included self-help with different forms of guidance (text messaging, phone and face-to-face sessions) and pure email therapy in the wider term internet-based treatment.

\section{Internet-based CBT}

Internet-based cognitive behaviour therapy has been proven effective in treating adults with many different psychiatric diagnoses. Hedman and colleagues (Hedman et al., 2012) found randomized controlled ICBT studies for 25 different clinical disorders. They found studies for depression, social phobia and panic disorder as meeting the highest evidence level according to standards set by the American Psychologist Association, thereby classifying them as well-established treatments. Apart from psychiatric and psychological problems, ICBT also shows promising results for somatic conditions such as tinnitus, headache and chronic pain and psychological 
distress associated with these conditions (Cuijpers, van Straten, \& Andersson, 2008; Hesser, Weise, Westin, \& Andersson, 2011).

The question whether ICBT is as effective as face-to-face CBT is interesting. A meta-analysis published in 2010 found no differences in outcome when comparing guided self-help (some of which were internetbased interventions) with face-to-face therapy for depression and anxiety (Cuijpers, Donker, van Straten, Li, \& Andersson, 2010a). Results were similar when examining follow up data in the same sample. Looking more closely at the available evidence, Andersson and colleagues conducted a systematic review and meta-analysis of studies comparing guided ICBT with group or individual face-to-face CBT (Andersson, Cuijpers, Carlbring, Riper, \& Hedman, 2014). A total of 13 studies on social anxiety disorder, panic disorder, depressive symptoms, body dissatisfaction, tinnitus and male sexual dysfunction met criteria for inclusion. The meta-analysis showed that these two methods of delivery resulted in comparable outcomes, which indicates that ICBT and face-to-face CBT might not differ when it comes to treatment effect. Although preliminary results point in this direction, the question of non-inferiority is hard to answer because of the problem with statistical power together with estimated effects when conducting this type of research (Cuijpers, 2016).

An important issue in internet-based treatment is the different ways of measuring and defining terms like adherence, dropout, compliance and attrition since how the terms are defined will affect how results are presented (Eysenbach, 2005). In their review and meta-analysis, Cuijpers and fellow researchers found indications that dropout was higher in guided self-help compared to face-to face treatment for depression (Cuijpers, Donker, van Straten, Li, \& Andersson, 2010a). The authors states that even though no significant differences were found, there were considerably variations in how drop-out was defined in the selected studies. This can also be seen in other reviews and meta-analyses as Kelders and colleagues defined adherence as a percentage of the intended usage of a web-based intervention (Kelders, Kok, Ossebaard, \& Van Gemert-Pijnen, 2012). By their definition, completing six out of eight modules would be an adherence of $75 \%$. And while other researchers also have defined adherence as a 
percentage of treatment modules completed, some have used an cut-off for dropout as completion of less than $75 \%$ of available modules (Karyotaki et al., 2015). It is only natural to consider dropout and low adherence as negative, but even if a patient drops out before completing the full treatment the effects can still be positive (Hilvert-Bruce, Rossouw, Wong, Sunderland, \& Andrews, 2012). This means we have to be careful when drawing conclusions from dropout- and adherence rates in studies.

Although not the main focus of this thesis, the translation of evidence from efficacy studies to a clinical setting is relevant for the dissemination of the method in regular care. Results from effectiveness studies are promising so far and comparable to those found in efficacy studies (Hedman et al., 2014; Ruwaard, Lange, Schrieken, Dolan, \& Emmelkamp, 2012). Attitudes towards ICBT in Sweden are very positive in primary care settings, while there are other countries were much work is needed when it comes to affecting patient (and therapist) attitudes towards digital treatment for depression (Topooco et al., 2017).

\section{Internet-based CBT for depression}

ICBT for depression has been widely studied. In the review by Hedman et al. (2012), twenty randomized controlled trials on depression from six different research groups were found, making trials on depression and depressive symptoms the most common finding. Several meta-analyses have summed up the evidence, showing that ICBT is an effective method for treating depression (Andrews, Cuijpers, Craske, McEvoy, \& Titov, 2010; Richards \& Richardson, 2012; Spek et al., 2007) and it seems that guided ICBT is as effective as established face-to-face treatments for this diagnostic group (Cuijpers, Kleiboer, Karyotaki, \& Riper, 2017). A frequently cited meta-analysis on internet-based treatment for depression, including 19 randomized controlled trials, showed a moderate pooled between group effect size of $d=.56$ (Richards \& Richardson, 2012). Even larger effects where found by Arnberg and colleagues, although they included fewer trials in their meta-analysis, as the pooled mean effect size was $d=.83$, (Arnberg, Linton, Hultcrantz, Heintz, \& Jonsson, 2014). Hedman et al. (2012) found a 
large within group effect size $(d=.94)$ when looking at pre- to postmeasurements in the treatment of depression.

Since ICBT has been proven effective for depression, there is also the question of how it holds up against the golden standard of face-to-face CBT. In a study comparing an adapted version of the material used in Paper I in this thesis with manualized group CBT, results showed that ICBT was noninferior and that effects were maintained at three year follow up (Andersson et al., 2013b). Evidence so far continuously points in the direction of similar effects. For example, a review containing five studies comparing ICBT with face-to-face CBT for depression showed equal results for these different ways of delivery (Andersson, Topooco, Havik, \& Nordgreen, 2016).

ICBT is a recommended method for treating depression in the Swedish health care (Socialstyrelsen, 2016). A study comparing the program used in Paper III with treatment as usual in a Swedish primary care setting (delivered at 16 primary care centres) showed no significant differences at post-measurement or at 12-month follow up (Eriksson et al., 2017; Kivi et al., 2014). The authors conclude that ICBT can be as effective as currently available methods in those primary care settings where the study was conducted (e.g. antidepressants, CBT, other psychotherapies, counselling). Another study in Sweden showed that patients in regular health care receiving a depression program based on the one used in Paper I, through a routine psychiatric setting, had large within effects on depression measured by MADRS-S (Hedman et al., 2014). Effects were maintained at six-month follow up.

Even though ICBT is the most studied method, there are also studies showing that other orientations such as psychodynamic (Johansson, Björklund, Hornborg, Karlsson, Hesser, Ljótsson, et al., 2013a) and interpersonal therapy (Donker et al., 2013) can be effective internet-based treatment methods for treating depression. 


\section{Specific treatment programs}

A variety of different computerized and internet-based programs for treatment of depression have been developed over the years (Saddichha, AlDesouki, Lamia, Linden, \& Krausz, 2014). Since there are different ways of delivering ICBT-programs, attempts have been made to specify specific commonalities that these different treatment programs share regarding ways of delivery, such as degree of synchronicity, program interactivity and multimedia channel of delivery (Proudfoot et al., 2011).

The material in Paper I was provided through an online platform used in an earlier study on the same program (Andersson et al., 2005). This online platform, Iterapi, has been in use for almost 20 years, and facilitates the delivery of internet-based treatment programs (Vlaescu, Alasjö, Miloff, Carlbring, \& Andersson, 2016). The self-help program in Study I was delivered in a similar way to most other ICBT-programs, using a fixed number of text-based modules delivered in a set order during a specified treatment period (Kelders et al., 2012). As the material in Study I was one of the first online programs for depression to be used in research, technology was not the focus of delivery and the Iterapi-platform has been updated and revised significantly since then. It is actually argued that keeping technology as basic as possible might have been a successful concept when first beginning to study the effects of self-help programs online (Andersson et al., 2008).

For Study III another web-based platform was used. The platform supported new ways of delivering content online, such as the addition of video and audio (see Table 3). These interactive elements were added make the material more motivating to work with. One of the consequences of using video and audio to deliver content in the treatment program in Study III was that it helped decrease the amount of text used. The total amount of text in the different self-help programs was approximately 45000 words in Study I, and 14500 words in Study III (including text in the workbook). A total of 22 minutes of video and 27 minutes of audio was also part of the latter program. How technology can be used to enhance motivation is a relatively new area of research when it comes to internet-based treatment. Attempts 
have been made to examine the role of technology in these types of interventions (Kelders et al., 2012). This research indicates that technology can play a part in increasing adherence and should be carefully considered when creating new solutions for providing internet-based treatment.

Table 3

Overview of two different self-help delivery formats

\begin{tabular}{lll}
\hline & Paper I & Paper III \\
\hline Text & Yes & Yes \\
Pictures & Yes & Yes \\
Video & No & Yes \\
Audio & No & Yes \\
Animations & No & Yes \\
Voice over & No & Yes \\
Quiz & Yes & No \\
Downloadable content & Yes & No \\
Offline workbook & No & Yes \\
Audio CD & No & Yes \\
Bookmark favourite & No & Yes \\
pages & & \\
Scheduled reinforcement & No & Yes \\
(through pop-ups) & &
\end{tabular}

\section{Blended treatment}

Although a clear definition is still lacking, blended cognitive behaviour therapy $(B C B T)$ is defined as a treatment format combining both face-toface sessions and online material (Kooistra et al., 2016). It has the advantage of preserving the face-to-face relation with patients and individualizing treatment, with the addition of easily accessible and well-structured online material. Recent attempts have been made to differentiate between integrated blended interventions, where online material and face-to-face session are provided within the same time period, and sequential blended 
interventions where online material is provided before or after face-to-face treatment such as in stepped care approaches (Erbe, Eichert, Riper, \& Ebert, 2017). Erbe and colleagues would consider the blended treatment used in Paper IV an integrated blended intervention based on their definition. The blended format could be a way to increase acceptance for internet-based interventions in the regular health care since it seems that stakeholders have positive attitudes towards this version of internet-based treatment (Topooco et al., 2017). Moreover, it can increase therapy intensity, which might increase effects (Cuijpers, Huibers, Ebert, Koole, \& Andersson, 2013b).

Providing digital tools for homework assignments and psychoeducation as an add-on to face-to-face CBT can be done with good effects (Månsson, Skagius Ruiz, Gervind, Dahlin, \& Andersson, 2013). In addition, surveys on counsellors using online tools such as email show that $97 \%$ use them in combination with face-to-face sessions (Chester \& Glass, 2006). Even so, to this date little is known about blended treatment and its effects. Results from outcome studies so far show preliminary positive results (Høifødt et al., 2013; Ly et al., 2015; Wright et al., 2005) and that it can be non-inferior to face-to-face CBT (Thase et al., 2017). To gain more knowledge about the effects of blended treatment compared to treatment as usual in primary care a large European project including eight countries, E-COMPARED, was put together (Kleiboer et al., 2016). The trial in Paper IV was part of that project.

The face-to-face sessions provided for the BCBT-group in Paper IV was delivered at week one, three, six and ten, and the online content used was based on material available from earlier CBT-studies for depression conducted in Sweden. The E-COMPARED consortium defined the overall format of delivery, but each individual research group decided the specifics of the study protocol. The protocol for the Swedish study had similarities with the structure of blended treatment provided in a previous study by the same research group (Ly et al., 2015). The number of face-to-face sessions, length of sessions and number of online modules are some of the basic components in blended treatment that have varied between studies (see Table 4). 
Table 4

A comparison of different formats for blended treatment.

\begin{tabular}{llll}
\hline & Study IV & $\begin{array}{l}\text { Høifødt et al. } \\
(2013)\end{array}$ & $\begin{array}{l}\text { Wright et al. } \\
(2005)\end{array}$ \\
\hline $\begin{array}{l}\text { Face-to-face } \\
\text { sessions }\end{array}$ & 4 & 7 & 9 \\
$\begin{array}{l}\text { Length of } \\
\text { sessions }\end{array}$ & $45 \mathrm{~min}$ & $15-30 \mathrm{~min}$ & $25 \mathrm{~min}$ \\
$\begin{array}{l}\text { Number of } \\
\text { online modules }\end{array}$ & 10 & 5 & 8 \\
$\begin{array}{l}\text { Length of } \\
\text { treatment }\end{array}$ & 10 weeks & 7 weeks & 9 weeks \\
Sequencing & Alternate & Alternate & Same occasion \\
\hline
\end{tabular}

\section{Email therapy}

In 2001, Mark Griffiths wrote an article in The Psychologist addressing the pros and cons with the rise of online therapy (Griffiths, 2001). He stated that "the most popular form of online therapy occurs by e-mail" (p. 1) and referred to the many online counselling sites available at that time. At that moment, it seemed that email therapy had the potential of being the new thing in psychology. However, in the same article Griffiths addresses the problem that few studies actually confirmed that email therapy was an effective treatment approach. Although commonly used by counsellors providing interventions online there is still a lack of studies on email therapy (Chester \& Glass, 2006). Email and asynchronous text communication have instead mostly been studied as an adjunct to internetbased self-help programs.

At the time of the first study in this thesis, no published manual for providing email therapy could be found. Therefore, the research group created a new manual that served as a framework for providing email therapy. Because of its comparison to guided self-help in the research study, the manual had to be distinctly different in several aspects compared to the 
self-help program. This affected how the CBT-content was delivered, the amount of time therapists spent per patient and the length of messages in the email group. No material from the self-help program, the email manual or other therapists' communication could be copy-pasted into the email communication with participants. The therapists were encouraged to keep to the manual, but also individualize the content based on the needs of the participant. The manual included recommendations regarding the content, structure and framework of email communication with participants, and advice on how to handle and give feedback on homework assignments attached to the emails. Email communication was divided into treatmentand assistant emails. Treatment emails were sent once a week and had the same function and similar content as modules in the self-help program, except that they were individualized to fit the participants' needs. They could also include questions, and feedback on homework exercises. Assistant emails were used to solve problems that made it difficult for the participants to work with the self-help program. This included questions about the platform or content participants did not understand.

\section{The role of therapist support}

Therapist effects in face-to-face psychotherapy are argued to be small to moderate (Wampold, 2015), making the role of therapist support in internetbased treatment is an interesting topic. In Andersson and Cuijpers metaanalysis, including 12 studies on computerized and internet-based CBT for depression, guided treatment yielded a moderate effect size of $d=.61$ compared to a low effect in the unguided group, $d=.25$ (Andersson \& Cuijpers, 2009). Another meta-analysis included even more studies $(n=19)$ and found that there were significantly larger effects for guided ICBT, $d=.78$, compared to unguided ICBT, $d=.36$ (Richards $\&$ Richardson, 2012). The analysis also examined rates of dropout depending on the type of support. Unsupported internet-based treatments had high dropout rates (78\%), whereas therapist-supported and administrative-supported treatments had dropout rates similar to those seen in face-to-face treatments according to the authors ( $28 \%$ and $38 \%$, respectively). In another review, Johansson and Andersson divided studies by means of therapist contact into four different categories: no contact before or during treatment, only contact 
before treatment, only contact during treatment and contact both before and during treatment (Johansson \& Andersson, 2012). Calculated effect sizes for these different categories showed that the more contact, the larger treatment effects on the main outcome.

Since guided treatment seems to be more effective than unguided, some of the questions that arise are: what amount of therapist time is needed, what format should the support have, what level of expertise is necessary for therapists and what should be included in the content of the communication (Baumeister, Reichler, Munzinger, \& Lin, 2014; Mohr, Cuijpers, \& Lehman, 2011; Titov et al., 2010). Almlöv and colleagues examined therapist effects in a sample containing data from two treatment studies on ICBT, including 10 therapists and 103 patients (Almlöv, Carlbring, Berger, Cuijpers, \& Andersson, 2009). Analyses indicated that ICBT therapy might be less sensitive to therapist effects on the main outcome measures. This finding is in line with the notion that the role of the therapist in ICBT might be of less importance, since the treatment format leaves less room for therapist input. The given format is independent of the therapist and also gives less experienced therapists more time to think before they interact with patients (Andersson \& Hedman, 2013).

Paxling et al (2013) analysed the email communication from three therapists providing internet-based treatment for generalized anxiety. They used content analysis to code therapist behaviours into eight different categories: deadline flexibility, task reinforcement, alliance bolstering, task prompting, psychoeducation, self-disclosure, self-efficacy shaping and empathic utterances. The most common behaviours were task prompting and selfefficacy shaping. Correlational analyses showed that task reinforcement affected both compliance and treatment effects in a positive way, while deadline flexibility had a negative association with outcome. A similar procedure was used by Holländare et al. (2016) to analyse content of emails between therapists and patients in ICBT treatment for depression. The most frequent therapist behaviour was encouraging, followed by affirmations and guiding. Out of the nine different themes found, six correlated with module completion, and several of the themes correlated with outcome at different time points (post-treatment and at two year follow up). However, results so 
far are mixed. Schneider and fellow researchers also analysed therapist behaviours in ICBT-treatment of depression (Schneider, Hadjistavropoulos, \& Faller, 2016). The text-communication from twenty-four therapists was included and in contrast to the study by Paxling and colleagues, several therapist behaviours were correlated with increased depression scores at post-treatment. In addition to examining therapist behaviours, attempts have been made to analyse and categorize patient behaviours in internet-based treatment for depression (Svartvatten, Segerlund, Dennhag, Andersson, \& Carlbring, 2015). Ten different categories were found by the authors and two of those were positively correlated with outcome, alliance and observing positive consequences.

The amount of time therapist spend on their patients varies from as high as 20 hours per participant (Ruwaard et al., 2012) to as low as less than one minute during the course of treatment (Mahoney, Mackenzie, Williams, Smith, \& Andrews, 2014). Usually though, therapists spend approximately between 10-20 minutes per participant and week in guided ICBT (Arnberg et al., 2014) which is commonly called minimal therapist contact (Kivi et al., 2014). The type of support and average therapist time per week for the treatment modalities included in this thesis can be seen in Table 5 .

Table 5

Amount and type of therapist support.

\begin{tabular}{|c|c|c|}
\hline Study & Type of support & $\begin{array}{l}\text { Average therapist time } \\
\text { per week (minutes) }\end{array}$ \\
\hline Study I (email) & Email & 64 \\
\hline Study I (self-help) & Email & 7 \\
\hline Study III (self-help) & Email & 12 \\
\hline $\begin{array}{l}\text { Study IV (blended } \\
\text { treatment) }\end{array}$ & Email and Face-to-face & $34^{\mathrm{a}}$ \\
\hline
\end{tabular}

${ }^{\mathrm{a}} 16$ minutes per week online and four face-to-face sessions á 45 minutes 


\section{Therapeutic alliance}

The term therapeutic alliance was introduced by Elisabeth Zetzel in 1956 and has ever since been a topic of interest in psychotherapy research (Catty, 2004). Although a term sprung from psychoanalytic theory, it has been integrated as a concept of therapeutic process that is present in a wide variety of theoretical orientations. It is argued to be an important aspect of psychotherapy with a well-established association between alliance ratings and treatment outcomes for several psychological treatments and a variety of psychological problems, including CBT-treatment for depression (Horvath, Del Re, Flückiger, \& Symonds, 2011). Although alliance might be perceived as a specific concept, it has been defined in a variety of ways and described as therapeutic alliance, working alliance, helping alliance and therapeutic bond (Martin, Garske, \& Katherine Davis, 2000). Attempts have been made to generalize the concept of alliance, making it possible to measure it across different psychotherapeutic orientations. The most successful attempt in doing this is Edward Bordin's pan-theoretical concept of working alliance (Bordin, 1979). According to Bordin's theory, alliance is based on the cooperation and shared view between therapists and patients of the context in which the therapeutic work is done. This theory deviated from previous concepts that emphasized the therapist's contributions and the role of the unconscious. Bordin laid out a conceptual framework of working alliance that he considered to be present in all forms of psychotherapy, and concluded that the effectiveness of therapy is a function of this. Working alliance is conceptualized as one general alliance factor, but with three specific sub-components. These are the degree of mutual trust and acceptance, which is closely linked to the human relationship between therapist and patient (Bond), consensus regarding the specific tasks in treatment (Task) and the mutual agreement on therapeutic goals (Goal).

It seems that Bordin's perspective on the therapeutic alliance have been integrated in the general conception of alliance. Martin and colleagues state in the introduction to their meta-analytic review that there are consensus regarding certain themes in alliance such as its collaborative nature, the affective bond between therapist and patient, and the ability to agree on mutual goals and tasks important for treatment (Martin et al., 2000). 


\section{Prediction of outcome}

Data on alliance shows a moderate, but robust, correlation with outcome in several meta-analyses and reviews. An early meta-analysis done by researchers at Simon Fraser University in Canada, based on 24 outcome studies, showed a moderate correlation of $r=.26$ between high alliance ratings and positive outcome in therapy (Horvath \& Symonds, 1991). Results also showed that this relation was not significantly different when controlling for treatment orientation or length of treatment, leading the authors to conclude that alliance seems to be of equal importance regardless of psychotherapeutic orientation. Martin and his colleagues at Ohio University used the same inclusion criteria as Horvath and Symmonds and included 79 studies in their meta-analysis (Martin et al., 2000). An overall weighted correlation of $r=.22$ was found between alliance and outcome, and the results were not influenced by other moderator variables included. A third meta-analysis, including 200 research reports, relied on data from previous meta-analysis with the addition of studies published between 2000 and 2009 (Horvath et al., 2011). The authors found a significant correlation of $r=.275$ between alliance and outcome, thus showing a similar result as the two previous meta-analyses. Conclusions drawn from these meta-analyses are that alliance can explain approximately $5-7 \%$ of the variance in outcome, which is argued to be one of the most influential factors in face-toface psychotherapy (Wampold, 2015).

The question is whether alliance causes symptom reduction, or if it is the other way around, that the reduction of symptoms causes high ratings of alliance. Some researchers argue that alliance might be therapeutic in itself, and correlations between alliance and outcome have been considered proof of this. In a large outcome study on patients with chronic depression, results showed that early alliance predicted subsequent improvement, even when controlling for early symptom improvement in depression (Klein et al., 2003) and recent research has shown that alliance ratings can predict improvement in depression between sessions (Falkenström, Ekeblad, \& Holmqvist, 2016). However, other studies have shown that it might be the other way around. Early symptom change in depression have been shown to correlate with subsequent alliance ratings, and some studies conclude that 
alliance does not predict outcome when controlling for symptom improvement (Webb, Beard, Auerbach, Menninger, \& Björgvinsson, 2014). These different findings have led to the examination of a reciprocal model, including alliance as both an outcome in therapy and a strategy for improved outcome (Xu \& Tracey, 2015).

\section{Therapeutic alliance in internet-based treatment}

The notion that alliance is created in the personal meeting between therapist and patient makes it even more interesting to look at alliance in internetbased treatment, where the degree and format of contact differs considerably from traditional ways of delivering therapy. If a therapeutic relation is dependent on the face-to-face meeting, interventions provided over the Internet should have lower alliance ratings. In fact, one could even question the very existence of alliance in a treatment format where most of the therapeutic content is provided as a text-based self-help program online.

Although not measures of alliance, several studies have gathered information on patient experiences of internet-based treatment, and the therapist contact provided in those settings. For example, in the study by Knaevelsrud and Maercker, $86 \%$ of the participants receiving treatment for posttraumatic stress experienced their contact with their online therapist as personal and $76 \%$ were positive to being treated online instead of by faceto-face CBT (Knaevelsrud \& Maercker, 2007). Ruwaard et al. (2009) found similar results were $87 \%$ experienced online therapy as pleasant and $89 \%$ did not miss face-to-face contact.

At the time of the first research study, that provided data for Paper I, and II, there were very few (if any) published articles on alliance in ICBT and email therapy. This need for increased knowledge led to the inclusion of a measurement of working alliance, to gather data regarding this concept in internet-based treatments. Since then, more data have been collected from different research groups although Sucala et al. (2012) found that only $1 \%$ of studies on e-therapy (defined as therapy provided through email, 
videoconferencing, virtual reality, chat or combinations of these) investigated the therapeutic relationship.

An early study by Cook and Doyle examined alliance ratings in a small sample of individuals $(n=15)$ receiving email and chat counselling for e.g. relationship issues and depression (Cook \& Doyle, 2002). Alliance ratings in this group were compared to a face-to-face group from another study, and no significant differences were found. Participants in the email group felt that their online therapy was a positive experience and they experienced a collaborative and bonding relationship with their therapists. Limitations with this study were the lack of power and using data from another study when comparing alliance ratings with those in face-to-face therapy.

In two separate randomized controlled studies published before the publication of Paper I, alliance in internet-based treatment was compared to a waiting list and a face-to-face treatment. In the trial by Knaevelsrud and Merker (2007) an internet-based treatment for Post-traumatic stress disorder (PTSD) was compared to a waiting list. Ninety-six participants were included and there was a significant increase in patient rated alliance during the progress of the treatment (alliance was measured week four and ten) and there was a correlation between ratings of alliance and outcome measures at post-measurement. In the second trial, 86 participants were included, and ICBT was compared with face-to-face treatment for panic disorder and agoraphobia (Kiropoulos et al., 2008). Participants in the ICBT group received a self-help program online and therapist contact weekly through email. Results showed that there was no significant difference between the two groups regarding alliance scores, indicating that alliance can be similar in internet-based treatment, even though less therapist time is offered and contact format is different. Another trial, conducted in 2013, examined alliance in online text-therapy and found alliance ratings comparable to those in face-to-face therapy (Reynolds, Stiles, Bailer, \& Hughes, 2013). An interesting finding was that participants appreciated the calming influence of the online environment and rated lower arousal levels during treatment than participants in the face-to-face therapy. Symptom severity, social support, therapist psychotherapy orientation and therapist experience did not affect the results. 
Comparing two different versions of support, Lindner et al. (2014) analysed the role of alliance if therapist contact was delivered through email or telephone. Participants were individuals from the control group (waiting list) in Paper III and received treatment with the same self-help program after eight weeks in the waiting list condition. There were no significant differences between groups regarding therapeutic alliance at week two, posttreatment and follow up, indicating that contact modality did not affect ratings of alliance. As for blended treatment, Ly et al. (2015), measured alliance in a treatment study comparing blended behavioural activation with face-to face behavioural activation. Ratings were comparable, both before treatment and at week three. Working alliance could predict outcome in the blended group, but not in the face-to-face group, which is a somewhat surprising find and adds to the need for deepened insight into the role of alliance in this treatment format.

Most studies on internet-based treatment so far have used patient-rated alliance and only a few studies have used therapist-rated alliance (Berger, 2017). Those few studies who have used therapist ratings have delivered a certain version of internet-based treatment, called Interapy, were patients are given online writing assignments twice a week and therapist spending 20-50 minutes per week and patient on individualized feedback (Knaevelsrud \& Maercker, 2007; Preschl, Maercker, \& Wagner, 2011). In these studies, correlations between therapist and patient ratings have been high.

\section{Measuring the therapeutic alliance}

Just as there are different ways of defining therapeutic alliance, there is also a plethora of ways to measure it (Elvins \& Green, 2008). A lack of consensus in defining alliance have led to the development of measuring instruments without a common point of reference. In a review by Horvath et al. (2011) more than 30 different instruments for measuring alliance were found, and even more if different versions of these were included. An attempt to summarize and recommend different scales commonly used to measure alliance was attempted by Martin et al. (2000). Out of the many 
different questionnaires used for measuring alliance, the Working Alliance Inventory was one of four scales that were considered having enough empirical evidence to be recommended by the authors for future use.

Alliance has been measured at different time points in treatment. A typical time for measurement seems to be at week three or four (Wampold, 2015). It can be argued that the time of measurement is important, but reviews and meta-analyses controlling for time of assessment have shown that there are no significant differences in results based on this factor (Horvath et al., 2011). Measurements have been developed in patient-, therapist- and observer rating versions. Early results showed tendencies for patient rated alliance to have a higher correlation with outcome than the other two (Horvath \& Symonds, 1991). However, more recent meta-analyses by Horvath and colleagues show that there seems to be no significant differences between type of rater and association with outcome (Horvath et al., 2011). Other meta-analytic studies have shown that even though therapist ratings of alliance have a moderately correlation with client ratings, it seems that clients rate their alliance more favourable than therapists (Tryon, Blackwell, \& Hammel, 2007).

\section{Working Alliance Inventory}

The Working Alliance Inventory (WAI) is based on the concept of working alliance by Bordin and is a well-established and frequently used scale to measure alliance in psychotherapy research. WAI has over the last ten years surpassed all other instruments regarding use in outcome studies (Mallinckrodt \& Tekie, 2016). It is available in patient, therapist and observer rating versions and research so far has shown its reliability, construct validity and predictive validity. It is also easily administered to both clients and therapists and developed to measure therapeutic relationships in an early phase of treatment (Tracey \& Kokotovic, 1989). The pan-theoretical concept makes it a recommended choice for measuring alliance regardless of psychotherapeutic orientation.

Many different versions of WAI have been developed and tested over the years. The first version included 36-items, with each question rated on a 7- 
point Likert-type scale, and a higher score indicating a more positive alliance (Horvath \& Greenberg, 1989). This scale was developed with the ambition to measure alliance in all forms of psychotherapy, and obtain a firm connection between the measurement and the underlying theory of alliance. From an initial pool of 91 items, the items included in the final instrument were selected through a process using experts on alliance (researchers) and professionals (psychologists). In an attempt to examine the predictive validity of the new instrument it was compared with two existing measurements of alliance. The results showed that WAI was significantly better as a predictor for patient rated outcome. Shortly thereafter, this 36item version was transformed into a 12-item questionnaire (Tracey \& Kokotovic, 1989). The authors selected four items from each subscale with the highest factor loadings and created a new, more easily administered instrument for measuring alliance. This version was named Working alliance - short form (WAI-S) and in a direct comparison with the original 36-item scale it has been shown to have comparable internal consistency and predictive validity (Busseri \& Tyler, 2003). Hatcher and Gillaspy used factor analysis to develop another 12-item version named Working alliance - short revised (WAI-SR; Hatcher \& Gillaspy, 2006). Seven items in this scale overlaps with the WAI-S version. It is argued by the authors that their version reflects Bordins theory in a more correct way. It highlights collaboration, has a more stable factor structure and a better differentiation between subscales (Task and Goal) than WAI-S. Using item response theory analysis, they also found difficulties with discrimination in the lower ends of the items in the WAI-S scale. Using a five-point Likert-type scale for items improved the quality of the scale. The WAI-SR has demonstrated good internal consistency when tested in outpatient, $\alpha=.90$, and inpatient samples, $\alpha=.93$ (Munder, Wilmers, Leonhart, Linster, \& Barth, 2010).

Since WAI consists of a general alliance measure and three subscales, the usefulness of these subscales have been examined by several researchers over the years. High correlations between subscales have led to the common use of one general alliance factor when studying and using WAI in clinical settings. When investigating the factor structure of WAI, Tracey and Kokotovic argued that their results supported the use of a bi-level model that included a primary general alliance factor and three secondary factors 
based on the specific subscales (Tracey \& Kokotovic, 1989). Some have argued for a three factor model, while the difficulties in separating the Goal and Task subscales have led other researchers to propose the two factor model (task/goal and bond) being used (Falkenström, Hatcher, \& Holmqvist, 2015). These different results and recommendations regarding the concept of alliance and its subcomponents has led to the use of subscales and total score in different combinations when examining the role of working alliance in psychotherapy research.

\section{Versions used in this thesis}

Since most research on alliance has been conducted in face-to-face settings, less is known about the alliance in settings that use fixed content (self-help programs), asynchronous text-communication online or other aspects different from the traditional patient-therapist perspective. Alliance questionnaires have been adapted in some of the papers in this thesis, as have been done in other internet-based treatment studies (Bergman Nordgren, Carlbring, Linna, \& Andersson, 2013). In Paper II a translated and slightly modified version of the 36-item WAI was used with the change of wording to better suit the use of an internet-based self-help program and email communication (words such as self-help treatment and email correspondence was used). A translated version of WAI-S, also adapted for use in internet-based treatment (e.g. the word therapy replaced by internettreatment), was used for the Generalized anxiety and Social anxiety sample, For Paper IV the questionnaire developed by Hatcher and Gillaspy was used in a translated version for patients and therapists. No specific changes were made to adapt to the blended treatment format. The 10-item therapist version also uses a five point Likert-type scale and has only been used in a few studies (Davison, 2007; McNaughton, 2016). Adapted for therapist use by Thomas Munder and colleagues, it substantially overlaps with the client version of WAI-SR and WAI-S. 


\section{Overall aim}

The overall aim of this thesis was to examine the effects of different treatment formats in internet-based CBT for depression and to further examine the role of therapeutic alliance in these treatment modalities. Specifically, by:

Examining the effects of an email therapy manual developed for the treatment of adult depression and compare it with an existing internet-based self-help program, and a waiting list control group, in a randomized controlled trial.

Examining the role of alliance in email therapy and internetbased self-help for adult depression (and in addition, social anxiety disorder and generalized anxiety disorder) regarding level of alliance and its ability to predict outcome.

Examining the effects of an internet-based guided self-help program for adults with depression, based on behavioral activation with ACT-components, against a waiting list control group in a randomized controlled trial.

Examining the role of alliance in blended treatment for adults with depression regarding level of alliance and its ability to predict change rate for depression during treatment. 


\section{Empirical studies}

Paper I. Vernmark K., Lenndin J., Bjärehed J., Carlsson M., Karlsson J., Öberg J., Carlbring, P., Eriksson, T., \& Andersson, G. (2010). Internet administered guided self-help versus individualized e-mail therapy: A randomized trial of two versions of CBT for major depression. Behaviour Research and Therapy, 48, 368-376.

Aim

The aim of this study was to examine the effects of a treatment manual for email therapy, compared with guided self-help and a waiting list control group, for individuals diagnosed with major depression.

\section{Methods}

Participants were recruited by means of newspaper articles in national and regional papers, a national radio interview regarding the study, posters at the University campus, and information on various web pages. A web page was created that included information about the study and the possibility to sign up for participation. Signing up for the study also required completion of four computerized questionnaires: BDI (Beck et al., 1961), MADRS-S (Svanborg \& Åsberg, 1994), Beck Anxiety Inventory (BAI; Beck, Epstein, Brown, \& Steer, 1988a), and the Quality of Life Inventory (QOLI; Frisch, Cornell, Villanueva, \& Retzlaff, 1992). These questionnaires were also used as outcome measures in the study (post-measurement and at six-month follow up). BDI was used as the main outcome measure of depression because of its good psychometric properties and frequent use in psychotherapy studies (Beck, Steer, \& Garbin, 1988b).

Participants who fulfilled the initial inclusion criteria were called to a live meeting where they were interviewed using the clinical version of SCID-I (SCID-I-CV; First et al., 1997). Six undergraduate students and a PhD student conducted the interviews. A psychiatrist then assessed the SCIDprotocols after the interviews. Two memory tests were also included in the 
interview: The Autobiographical Memory Test (AMT; Williams \& Broadbent, 1986) and the Future Thinking Task (FTT; MacLeod, Rose, \& Williams, 1993).

Criteria for inclusion were (a) being at least 18 years, (b) a total of $<31$ on MADRS-S, (c) a total of $>14$ on MADRS-S, (d) $<4$ on Item 9 (suicidal thoughts) on MADRS-S, (e) no medication for depression or unchanged dosage of medication for depression during the last month, (f) not participating in other treatment for depression at the time, (g) not having other primary disorder that needed different treatment or that could be affected negatively by the treatment, (h) being diagnosed with major depression according to DSM-IV. A total of 280 persons signed up for the study and 132 were excluded after initial screening (a-f). Out of the 148 who met inclusion criteria, 25 persons did not want to participate, 23 persons did not show up for the interview and 12 were excluded after the interview (gh). A total of 88 persons were randomized to one of three groups.

Other than the questionnaires used, SCID-I (Module A - Depression) and an abbreviated version of the Clinical Global Improvement scale (CGI; Guy, 1976) was administered at post-treatment and at six-month follow-up. Blind assessors who had no earlier contact with the participants and no knowledge of which group they had been randomized to made all follow-up interviews. At six-month follow-up, both the SCID-I (Module A - Depression) and CGI were conducted by telephone.

Six psychology M.Sc. students served as therapists for both treatment groups and all therapists received group supervision once a week by a licensed psychologist. Therapists were randomly assigned to participants in each group. The self-help program was based on material used in an earlier study (Andersson et al., 2005) and consisted of seven text modules. Participants were prompted to spend approximately one week per module. The material included an introduction to CBT, depression from a CBTperspective, behavioural activation, cognitive restructuring, sleep management, defining goals/values and relapse prevention. Each module was available online and also as downloadable file in PDF-format on the website. A therapist manual was created for the email therapy. The manual was based on the same CBT-principles used in the self-help program, with 
added focus on case conceptualization and functional analysis. It served as a framework for the individualized treatment and no material could be directly copied from the self-help program. Participants could attach homework assignments to their emails and generally received one treatment mail per week from therapists. During the weekly supervision, the content of communication in email therapy was discussed and audited to ensure allegiance to the manual. Both treatments lasted for eight weeks and the control group received the guided self-help treatment after this period.

Table 6

Demographic description of the participants

\begin{tabular}{|c|c|c|c|c|}
\hline & $\begin{array}{l}\text { Email } \\
(n=30)\end{array}$ & $\begin{array}{l}\text { Self-help } \\
(\mathrm{n}=29)\end{array}$ & $\begin{array}{l}\text { Control } \\
(\mathrm{n}=29)\end{array}$ & $\begin{array}{l}\text { Total } \\
(\mathrm{n}=88)\end{array}$ \\
\hline \multicolumn{5}{|l|}{ Gender } \\
\hline Female & $21(70 \%)$ & $23(79.3 \%)$ & $16(55.2 \%)$ & $60(68.2 \%)$ \\
\hline \multicolumn{5}{|l|}{ Age } \\
\hline Mean age $(S D)$ & $40.5(13.9)$ & $37.2(13.0)$ & $32.7(10.6)$ & $36.82(12.9)$ \\
\hline \multicolumn{5}{|l|}{ Marital status } \\
\hline $\begin{array}{l}\text { Married or } \\
\text { cohabiting }\end{array}$ & $18(60 \%)$ & $17(58.6 \%)$ & $10(34.5 \%)$ & $45(51.5 \%)$ \\
\hline Other $^{\mathrm{a}}$ & $12(40 \%)$ & $12(41.4 \%)$ & $19(65.5 \%)$ & $43(48.5 \%)$ \\
\hline \multicolumn{5}{|l|}{ Educational level } \\
\hline University $^{\mathrm{b}}$ & $23(76.6 \%)$ & $26(89.6 \%)$ & $23(79.3 \%)$ & $72(81.8 \%)$ \\
\hline Other $^{\mathrm{c}}$ & $7 \quad(23.4 \%)$ & $3(10.4 \%)$ & $6 \quad(20.7 \%)$ & $16(18.2 \%)$ \\
\hline \multicolumn{5}{|l|}{ Employment } \\
\hline Employed & $18(60 \%)$ & $8 \quad(27.6 \%)$ & $11(37.9 \%)$ & $37(42.0 \%)$ \\
\hline Student & $5 \quad(16.7 \%)$ & $11(37.9 \%)$ & $10(34.5 \%)$ & $26(29.5 \%)$ \\
\hline Other $^{\mathrm{d}}$ & $7 \quad(23.3 \%)$ & $10(34.5 \%)$ & $8 \quad(27.6 \%)$ & $25(28.5 \%)$ \\
\hline
\end{tabular}

The primary analyses were based on the intention-to-treat principle and use of the first available observation brought forward. Significance testing of 
group differences regarding demographic data and pre-treatment measurements was conducted using ANOVA and $\chi^{2}$ tests. Differences between groups regarding pre- and post-measurements were tested with a 2 (group) x 2 (time) ANOVA. For post hoc testing of significant interactions Tukey's HSD was used. Also, a mixed effects model with an AR1 covariance pattern and a restricted maximum likelihood model (REML) were used as a second way to analyse data. This was done to account for dropouts without assuming that the first measurement was stable. Effect sizes (Cohen's $d$ ) were calculated both within and between groups. Clinical significance was defined and calculated in three ways: the proportion of participants no longer fulfilling the diagnostic criteria for major depression, the proportion of participants being rated as very much or moderately improved according to the CGI and finally the proportion reaching highend-state functioning as defined by Jacobson and Truax (Jacobson \& Truax, 1991). A total of $19.3 \%$ of the participants was on medication for depression (stable for at least one month), $38 \%$ had a comorbid diagnosis and $46.6 \%$ had an earlier history of psychotherapy. More information about participants at pre-treatment can be found in Table 6 .

\section{Results and discussion}

Participants in the self-help condition completed an average of six modules during the eight weeks of treatment and each therapist spent an average of 53 minutes $(S D=28$, range $=10-165)$ per participant in this group. The total average time spent by each email therapist per participant in the email condition was $509 \mathrm{~min}(S D=176$, range $=171-890)$ and an average of eight treatment emails (one per week) were sent to each participant. There were no significant between-group differences at pre-treatment, and dropout from responding to online questionnaires at post-measurement and follow-up was $3 \%$ and $15 \%$, respectively.

There was a significant interaction effect for group and time on BDI, $F$ $(2,85)=6.47, p<.001$. Post hoc testing with Tukey's HSD showed that the email participants were significantly improved compared to the waiting-list condition ( $p=.002$ ) with an effect size of $d=.96$. The self-help group were in proximity of the $p<.05$ criteria $(p=.06)$, with an effect size of $d=.56$. The 
two treatments did not differ $(p=.41)$. There was also a significant interaction effect for group and time on MADRS-S, $F(2,85)=5.83, p=.003$. Post hoc testing with Tukey's HSD showed that the email therapy group was significantly improved compared to the waiting list condition $(p=.005)$, but the self-help group was not $(p=.74)$. For BAI there was no significant interaction effect for group and time, $F(2,85)=.13, p=.126$, and this was also the case for QOLI, $F(2,85)=1.17, p=.32$.

At six-month follow-up, there were continued improvement in both groups (email and the combined self-help group) and no significant between-group differences on either of the outcome measures. Large within effect sizes were seen for both the email group and self-help group, both at posttreatment $(d=2.27$ and $d=1.46)$ and at six-month follow up $(d=2.42$ and $d=1.56)$.

Using the mixed models approach the interaction effect on BDI was replicated $F(2,84.1)=7.6, p=.001$, with both treatment groups being superior to the waiting-list group. At six-month follow-up, the repeated measures effects were highly significant $(p<.001)$, and there was no interaction between time and treatment condition, leading to the conclusion that using the mixed model procedure to handle data did not alter the main findings.

Three measures of clinical significance were calculated in two different ways, one using only completers and the other using first baseline observation carried forward for missing data (presented within connotations below). At post-treatment $93 \%(83 \%)$ of the participants in the email therapy condition, $83 \%(74 \%)$ in the self-help condition and $28 \%(25 \%)$ in the waiting-list condition no longer fulfilled the criteria of major depression according to DSM-IV. At six-months the numbers were 96\% (90\%) for email therapy and $78 \%(68 \%)$ for the combined self-help group. Regarding the CGI at post-treatment, $74 \%(71 \%)$ in the email therapy condition were rated as very much improved or moderately improved. The result for the guided self-help group was $46 \%(41 \%)$, and $16 \%$ (15\%) in the waiting-list condition. At six-month follow up the email therapy participants rated as very much or moderately improved had decreased to $52 \%(47 \%)$ and for the combined self-help group there was an increase to $57 \%(46 \%)$. 
To reach high-end-state functioning the participant had to have a score between zero and eight on BDI and a Reliable change index of at least 1.96. At post-treatment $31 \%$ (30\%) in the email therapy condition, 37\% (35\%) in the self-help condition and 14\% (14\%) in the waiting list condition reached high-end-state functioning. At six-months the numbers were 52\% (43\%) in the email therapy condition and $56 \%(47 \%)$ in the combined self-help group.

There were no effects of pre-treatment medication status, gender, or presence of co-morbidity on BDI change scores. Moreover, there was no correlation between change on the BDI and age, computer knowledge, previous treatment or any other of the pre-treatment variables. Also, there was no correlation between outcome and number of modules completed in the guided self-help treatment or number of treatment emails sent from therapists. No indication of therapist drift was observed during treatment.

Although there were minor differences in effect between the two active treatments, both were superior to a waiting-list control group on the main outcome measure at post-measurement. Large within effect sizes that were sustained at six-months follow-up were also observed and over half of the participants reached high-end-state functioning at follow-up in both groups. These findings replicate previous studies on guided internet-based self-help for depression (Andersson et al., 2005). Unexpectedly, there was large improvement in the control group that affected the between group effect sizes for both treatments. This has been observed in earlier trials (Ström, Pettersson, \& Andersson, 2004; Zetterqvist, Maanmies, Ström, \& Andersson, 2003) and may in this study be caused by the test procedures (e.g., thorough diagnostic interviews, memory tests, questionnaires) or spontaneous improvements. However, the categorical outcomes clearly show that participants who received treatment had a higher degree of clinically significant change. We did not find any significant interactions for the secondary outcome measures, which suggests that there is room for improvement regarding comorbid anxiety and change in quality of life when it comes to both treatment modalities. 
This was one of the first controlled trials on email therapy and the individualized treatment format showed a large between-group effect size on BDI compared to the waiting list. Several measurements were in favour of the email condition compared to the self-help condition. However, it was not conclusive enough to reach the conclusion that email therapy is a better option, especially when looking at clinically significant improvement and follow-up measurements. 
Paper II. Andersson, G., Paxling, B., Wiwe, M., Vernmark, K., Bertholds Felix, C., Lundborg, L., Furmark, T., Cuijpers, P., $\varepsilon$ Carlbring, P. (2012). Therapeutic alliance in guided Internetdelivered cognitive behavioral treatment of depression, generalized anxiety disorder and social anxiety disorder. Behaviour Research and Therapy, 50, 544-550.

\section{Aim}

The aim of this paper was to examine the role of alliance in internet-based CBT for depression, generalized anxiety disorder and social anxiety disorder.

\section{Methods and results}

\section{Depression}

Data collected during Study I was used for this analysis. All participants were interviewed live, but self-report instruments including alliance ratings were collected through online questionnaires. Participants in the email therapy and the self-help condition both had an online therapist who guided them through the eight-week treatment period. A total of 88 persons with a confirmed diagnosis of major depressive disorder were included in the trial. Participants were asked to answer an alliance questionnaire following the third treatment week. By then participants had been interviewed in a live structured interview (not conducted by the therapist), had started their treatment, and had been in contact with their online therapist at least three times. The treatment provided was either email therapy or guided self-help. All emails were individually written for the specific participant. The total average time spent by therapists on each participant in the email therapy was $509 \mathrm{~min}$. Therapists $(n=6)$ were identified with name and a picture on the study web page. The guided internet-based guided self-help consisted of text chapters dealing with CBT components such as behavioural activation and cognitive restructuring and was used in Paper I. Each therapist spent an average of 53 minutes per participant for the whole self-help treatment. Homework assignments were given to both groups. A total of 59 individuals 
were randomly allocated to email therapy $(n=30)$, self-help $(n=29)$ or a waiting list control group $(n=29)$.

A total of 49 participants in the treatment groups completed the alliance measure. Non-responders were evenly distributed between the groups. Mean age for these participants was 38.9 years $(S D=13.5)$, and $75 \%$ were women. There were no differences between the two treatment groups in terms of age and gender.

The BDI (Beck et al., 1961) was used as the primary outcome measure for depression in the analysis. Residual gain scores were calculated, which handle measurement error of repeated administration of the instruments and the initial differences between individuals at pre-treatment (Steketee \& Chambless, 1992). Residual gain scores were reversed so that higher scores would indicate greater improvement.

In order to measure therapeutic alliance, we used an adapted online version of the WAI with 36 items (Horvath \& Greenberg, 1989). The adaptation consisted of minor reframing of items to fit with the internet-based treatment. Each item on the questionnaire was rated on a 7-point scale, with higher scores indicating higher alliance. Alliance was only measured from the participant point of view. A total score for the WAI was calculated, and also scores for the three subscales. Psychometric properties were $\alpha=.81$ for the Task subscale, $\alpha=.84$ for the Goal subscale, and $\alpha=.90$ for the Bond subscale. For the total score, the internal consistency was $\alpha=.91$. In addition, there were high intercorrelations between the total score and the subscales $(r=.67$ to $r=.92)$.

Mean ratings for the email therapy group was: total score $(M=5.58$, $S D=.82)$, Task $(M=5.23, S D=.83)$, Goal $(M=5.63, S D=.86)$ and Bond $(M=5.86, S D=.91)$. Mean ratings for the guided self-help group was: total score $(M=5.25, S D=.82)$, Task $(M=5.19, S D=.84)$, Goal $(M=5.08, S D=.92)$ and Bond $(M=5.47, S D=.97)$. Non-completers of the WAI did not differ with regard to age, pre-treatment BDI, or residual change scores on the BDI. There were no between group differences with the exception of the WAI subscale Goal for which the email therapy group scored significantly higher, 
$t(47)=2.17, p=.035$. None of the correlations were statistically significant and results were unchanged when adding age as a covariate. The WAI was finally correlated with age and pre-treatment BDI scores. While there was a significant correlation between WAI total score and age $(r=.33, p=.02)$, there was no significant correlation with pre-treatment BDI scores $(r=.21)$.

\section{Generalized anxiety disorder}

Data were collected during a controlled study on ICBT for Generalized anxiety disorder (Paxling et al., 2011). Participants were screened online and thereafter interviewed over the telephone. Self-report instruments and alliance ratings were collected through online questionnaires. Participants had an online therapist who guided them through the eight-week treatment period. Following screening and interview 89 persons diagnosed with GAD were included and were randomized to either wait-list control $(n=45)$ or a treatment $(n=44)$. More details regarding procedures and treatment outcomes are provided in Paxling et al. (2011).

Alliance ratings were completed during the third treatment week. Participants had been in contact with the research staff and their therapist at least three times and had begun to send in their homework assignments. The online therapists $(n=3)$ were identified with name and a picture on the study web page. The treatment in the study was guided self-help with weekly feedback sent to the participants, but also occasional answers to questions that could arise during the treatment. The treatment was text-based and contained modules on psychoeducation, applied relaxation, worry time, cognitive restructuring, problem solving, worry, interpersonal problem solving, sleep management and finally relapse prevention. The therapist time devoted to each client ranged from 10 to 15 min per week, with an average total time of 97 minutes per participant $(S D=52$, range=12-215). A total of 35 completed both alliance measures and post-treatment measurements. Mean age was 40 years and $80.6 \%$ were women.

The primary outcome measure in the trial was the Penn State Worry Questionnaire (PSWQ; Meyer, Miller, Metzger, \& Borkovec, 1990). It has good psychometric properties and has been used in previous ICBT studies (Titov et al., 2009). As a measure of therapeutic alliance, the 12-item 
version of the WAI-S with a 7-point Likert-type scale was used (Tracey \& Kokotovic, 1989). Psychometric properties for the online version of the WAI-S was $\alpha=.84$ for the Task subscale, $\alpha=.69$ for the Goal subscale, and $\alpha=.83$ for the Bond subscale. For the total score the internal consistency was $\alpha=.91$. There were high intercorrelations between the total score and the subscales ( $r=.69$ to $r=.93)$.

Mean ratings for the guided self-help group was: total score $(M=5.63$, $S D=.94)$, Task $(M=5.60, S D=1.03)$, Goal $(M=5.88, S D=.94)$ and Bond $(M=5.43, S D=1.12)$. As reported in the trial the treatment group improved, and for the group who completed the WAI-S the within group effect size on the PSWQ was $d=1.17$. We checked if the non-completers differed from the ones who completed the WAI-S and there were no significant differences with regards to age, pre-treatment PSWQ or residual change scores on the PSWQ (unpaired t-tests). Analyses showed that correlations between alliance and outcome were not statistically significant. The WAI-S was finally correlated with age and pre-treatment PSWQ scores and age, and no significant correlations were found.

\section{Social anxiety disorder}

Data for this sample were collected in association with a controlled study on ICBT for Social anxiety disorder (Andersson, Carlbring, Furmark, \& on behalf of the SOFIE Research Group, 2012a). Similar to the other samples participants were screened online and then interviewed to obtain a DSM-IV diagnosis of SAD. Self-report instruments, including the WAI-S, were collected online. The guided ICBT treatment lasted for nine weeks and each participant communicated with an online therapist during the trial. Following screening and interview 204 individuals diagnosed with SAD were randomized to either an online discussion control group $(n=102)$ or a treatment group $(n=102)$. More details regarding procedures and treatment outcomes are provided in Andersson et al. (2012a).

Alliance ratings were collected during the fourth week of treatment. Name and a picture on the study web page identified therapists. The ICBT treatment for SAD has been tested in several previous controlled trials (Carlbring, Furmark, Steczkó, Ekselius, \& Andersson, 2011; Furmark et al., 
2009) and consists of an introductory module describing SAD, cognitive restructuring, exposure exercises, attention training, social skills and relapse prevention. The treatment is guided with weekly feedback sent to the participants and on occasion answers if problems arise. On average, therapists $(n=13)$ spent 15 min per week providing feedback to each participant (exact time not collected). A total of 90 individuals completed both alliance and post-treatment measurements. Mean age of the 90 participants was 37.7 years, and $59.3 \%$ were women.

The primary outcome in the SAD trial was the Liebowitz Social Anxiety Scale self-report version (LSAS-SR; Baker, Heinrichs, Kim, \& Hofmann, 2002). The LSAS-SR has good psychometric properties, and has also been validated for online use (Hedman et al., 2010). The same 12-item online version of WAI-S was used in this study. Psychometric properties was $\alpha=.88$ for the Task subscale, $\alpha=.79$ for the Goal subscale, and a $\alpha=.89$ for the Bond subscale. For the total score the internal consistency was $\alpha=.94$. There were also high intercorrelations between the total score and the subscales $(r=.81$ to $r=.94)$, suggesting that the subscales and total score overlap substantially.

Mean ratings for the guided self-help group was: total score $(M=5.45$, $S D=1.05)$, Task $(M=5.24, S D=1.16)$, Goal $(M=5.61, S D=.98)$ and Bond $(M=5.5, S D=1.22)$. In terms of treatment outcome, the treatment group improved with a within-group effect size of $d=.97$ on the LSAS-SR. The few non-responders to the WAI-S did not differ from the completers (with regards to age, pre-treatment LSAS-SR or residual change scores on the LSAS-SR). Correlations on WAI-S with outcome were not statistically significant. The WAI-S was finally correlated with age and pre-treatment LSAS-SR scores and no significant correlations were found.

\section{Discussion}

Therapeutic alliance is often regarded as an important factor in psychotherapy outcome research, with a robust but modest correlation with outcome (Horvath et al., 2011). The role of alliance in ICBT is not well investigated, however there are examples of studies in which high alliance 
ratings had been obtained for this treatment format (Knaevelsrud \& Maercker, 2007; Ljótsson et al., 2011). In all three samples, we found high ratings of alliance with mean scores for the total and subscales in line with what have been found in face-to-face treatments (Busseri \& Tyler, 2003). Moreover, the psychometric properties of the WAI and WAI-S were good across all samples with high internal consistency for all subscales and the total score. In the Depression sample, we found one statistically significant difference in favour of email therapy on the WAI goal subscale. This difference could be explained by the lower contact time in the guided selfhelp group, since the mean goal subscale score for the email group was similar to what was found in the other samples. It could also be an effect of the addition of an individual functional analysis and case conceptualization in the early treatment stages for those participants in the email group.

In line with results reported by other researchers, correlations in our three samples were in a positive direction but not statistically significant (Knaevelsrud \& Maercker, 2006). Statistical power could have an impact on these findings, but when all three samples were pooled there was still no significant association between total score on the alliance questionnaires and residualized change scores on the main outcome measures.

Given the minimal amount of therapist contact in certain ICBT-treatments, it would not be surprising if alliance ratings had been lower than in face-toface therapies. However, the WAI and WAI-S are focused on concrete aspects of the therapy (task and goal) and it may be that the clients relate to the self-help material as well as the therapist. Indeed, it has been suggested that alliance-fostering aspects are included in self-help texts (Richardson, Richards, \& Barkham, 2010).

Alliance ratings were collected early in the treatment process, but it is still possible that the high ratings are a consequence of treatment effects rather (Webb et al., 2011). Moreover, alliance may fluctuate over the therapy process, which would require repeated measures to establish if fluctuations influence outcome. 
Paper III. Carlbring, P., Hägglund, M., Luthström, A., Dahlin, M., Kadowaki, A., Vernmark, K. \& Andersson, G. (2013). Internetbased behavioral activation and acceptance-based treatment for depression: a randomized controlled trial. Journal of Affective Disorders, 148, 331-337.

\section{Aim}

The aim of this paper was to examine the effects of an interactive ICBTprogram (based on behavioural activation with ACT-components), for individuals diagnosed with depression, compared to a waiting list condition.

\section{Methods}

Participants were recruited from the general public by advertising in a Swedish newspaper and interested participants were instructed to sign up for the trial at the study website. Screening was conducted with online versions of the MADRS-S (Svanborg \& Åsberg, 1994), BDI-II (Beck et al., 1996), BAI (Beck, Epstein, Brown, \& Steer, 1988a) and QOLI (Frisch et al., 1992). All questionnaires have demonstrated good psychometric properties even when administered online (Carlbring et al., 2007; Holländare et al., 2010). The measures were later used as outcome variables in the trial with BDI-II as the main outcome.

To be included in the study the participants had to: (a) be at least 18 years of age; (b) live in Sweden; and (c) have a MADRS-S score in the range of 1530. Participants who fulfilled the initial inclusion criteria $(a-c)$ were telephoned and subsequently interviewed by two M.Sc. clinical psychology students using module A from the SCID-I (First et al., 1997). A psychiatrist then assessed the SCID protocols after the interviews. All participants had to fulfill the criteria for major depressive disorder according to the DSM-IV (APA, 2000). The presence of dysthymia was also assessed.

Of the 215 individuals who initially expressed interest in the study, 80 were subsequently included after the diagnostic interview. Those randomized to 
the treatment group received internet-based self-help including minimal therapist contact by two clinical psychology M.Sc. students who had completed their clinical training. Participants in the waiting list control group received the same treatment as above after the post-assessment had been performed. The treatment material used in this study was a commercially available program called Depressionshjälpen. The program has a focus on behavioural activation with ACT-influences and is divided into seven modules to be finished in a predetermined order during 10 weeks. All modules were available online and consisted of text, videos, sound clips, pictures and narrated animations. In addition to the online content the participant was also provided with a workbook (on paper) and a CD with mindfulness and acceptance exercises. Therapists had weekly contact with participants through secure email and feedback was mainly focused on validating participants experience, reinforce progress, provide feedback on homework assignments and encouraging continuous work with the treatment. Feedback was usually given within 48 hours and the internet therapists had weekly supervision with a licensed psychologist.

Baseline between-group differences in demographic data and pre-treatment measures were analyzed with independent t-tests and chi-square tests. An intention-to-treat design was used in analyses. Missing data at posttreatment was $2.5 \%$ and at follow up $7.5 \%$. Response rate for weekly MADRS-S measurements ranged between a low of $77.5 \%$ at week six and a high of $91.3 \%$ at week three. Between-group changes in questionnaire scores were analyzed using univariate ANCOVA, assigning pre-treatment scores as the covariate. Within-group changes in questionnaires were analyzed using paired-samples t-tests. Effect sizes (Cohen's $d$ ) were calculated for within- and between-group changes, using the pooled standard deviation.

Clinically relevant improvement was calculated using the proportion of individuals reaching a score of 10 or below on the BDI-II, which was considered an easily understood cut-off for defining clinically relevant improvement. The difference in recovery rate was tested by means of Fisher's exact test. 
At pre-treatment a total of $13.8 \%$ of the participants was on medication for depression (stable for at least three months), $62.5 \%$ had an earlier history of psychotherapy and $17.5 \%$ fulfilled the criteria for comorbid dysthymia. For more info about participants, see Table 7.

Table 7

Demographic description of the participants

\begin{tabular}{|c|c|c|c|}
\hline & $\begin{array}{l}\text { Treatment } \\
(\mathrm{n}=40)\end{array}$ & $\begin{array}{l}\text { Control } \\
(\mathrm{n}=40)\end{array}$ & $\begin{array}{l}\text { Total } \\
(n=80)\end{array}$ \\
\hline \multicolumn{4}{|l|}{ Gender } \\
\hline Female & $31(77.5 \%)$ & $35(87.5 \%)$ & $66(82.5 \%)$ \\
\hline \multicolumn{4}{|l|}{ Age } \\
\hline $\begin{array}{l}\text { Mean age } \\
(S D)\end{array}$ & $43.6(13.7)$ & $45.3(13.4)$ & $44.4(13.5)$ \\
\hline \multicolumn{4}{|l|}{ Marital status } \\
\hline $\begin{array}{l}\text { Married or } \\
\text { cohabiting }\end{array}$ & $23(57.5 \%)$ & $18(35 \%)$ & $41(51.3 \%)$ \\
\hline Other $^{1}$ & $17(42.5 \%)$ & $22(65 \%)$ & $39(48.7 \%)$ \\
\hline \multicolumn{4}{|l|}{$\begin{array}{l}\text { Educational } \\
\text { level }\end{array}$} \\
\hline University $^{2}$ & $28(70 \%)$ & $33(82.5 \%)$ & $61(76.3 \%)$ \\
\hline Other $^{3}$ & $12(30 \%)$ & $7 \quad(17.5 \%)$ & $19(23.7 \%)$ \\
\hline \multicolumn{4}{|l|}{ Employment } \\
\hline Employed & $31(77.5 \%)$ & $25(62.5 \%)$ & $56(69.9 \%)$ \\
\hline Student & $3(7.5 \%)$ & $6(15 \%)$ & $9 \quad(11.3 \%)$ \\
\hline Other $^{4}$ & $6 \quad(15 \%)$ & $9 \quad(22.5 \%)$ & $15(18.8 \%)$ \\
\hline
\end{tabular}

${ }^{1}$ Single, in a relationship but living alone or widow

${ }^{2}$ Completed or ongoing

${ }^{3}$ Elementary school, upper secondary school or vocational training

${ }^{4}$ Unemployed, retired or registered sick

\section{Results and discussion}

Dropout rate was low in this trial $(n=2)$ and treatment was superior to control with significant interactions on all measures except for quality of life: BDI-II $(F(2,77)=21.63, p=.000)$, MADRS-S $(F(7,71)=3.36, p=.002)$, BAI $(F(2,77)=40.16, p=.000)$, QOLI $(F(2,77)=2.11, p=.128)$. On the main 
outcome measure (BDI-II) the between group effect size was $d=.98(95 \%$ $\mathrm{CI}=0.51-1.44)$ and treatment gains were maintained at the three-month follow-up in the treatment condition, $d=1.11$ (pre vs. post) and $d=1.36$ (pre vs. follow up). The proportion of persons reaching the criteria of having a score of $\leq 10$ on the BDI-II at post-treatment was $25 \%(10 / 40)$ in the treatment group and 5\% (2/40) in the control group. This difference was significant (Fishers exact test, $p=.016$ ). There was no deterioration, defined as an increased BDI-II score of $\geq 10$ points after treatment. A subsequent analysis was made to explore if the presence of a comorbid dysthymia had any impact on treatment outcome. There was no difference in the pretreatment scores on the primary outcome measure $(t(38)=0.29, p=.78)$ and there was no difference in the change scores $(t(38)=0.24, p=.81)$. Hence, dysthymia did not moderate outcome. The mean time spent by therapist per participant was 12 minutes per week and there was no statistically significant difference between the two therapists in terms of time spent in minutes and change scores on the BDI-II. The participants finished an average of five out of seven modules during the eight weeks of treatment.

The effect on the BDI-II was large in terms of the between group effect size and comparable to outcomes seen in earlier ICBT-studies (Richards \& Richardson, 2012) and behavioral activation in face-to-face settings (Cuijpers, van Straten, \& Warmerdam, 2007). The proportion of persons who reached clinically relevant improvement was only $25 \%$ using a score of $\leq 10$ on BDI-II. A score of 13 and below is considered minimal depression and using this criterion for clinically relevant improvement might have changed the results on this outcome (Wikberg et al., 2015). We found no effects of the presence of dysthymia, which implies that the treatment might work for individuals with more longstanding symptoms of depression. This needs to be replicated with larger samples and specific focus on dysthymic patients.

Weekly measurements with MADRS-S showed large changes in the control group and there was only a significant difference at week seven and postmeasurement between groups. Improvement on this measure of depression could be affected by the repeated use of the instrument during treatment or 
be an effect of spontaneous improvement seen in waiting list groups used in psychotherapy studies (Rutherford et al., 2012).

It is not clear how much the ACT-components and the extra features like videos and audio files added in terms of outcome and compliance. With this in mind this study shows that there is initial evidence for behavioral activation in an interactive format with incorporated components of acceptance-based and mindfulness as an effective treatment for depression. 
Paper IV. Vernmark, K., Hesser, H., Topooco, N., Berger, T., Riper, H., LuUk, L., Backlund, L., Carlbring, P., \& Andersson, G. (2017). Working alliance as a predictor of change in depression during blended cognitive behavior therapy. Manuscript submitted for publication.

\section{Aim}

The overall aim of this paper was to examine the role of alliance in blended treatment and if patient- and/or therapist rated alliance could predict change scores in depression during treatment.

\section{Methods}

The data in this study were collected from a randomized controlled trial comparing blended cognitive behaviour therapy (BCBT) with treatment as usual (TAU). The study was part of a large European project, the ECOMPARED project (Kleiboer et al., 2016). Participants were recruited from mental health care centres in Sweden where they also received information about the trial. Clinicians were instructed to recommend participants with depressive symptoms to sign up for the study through the study website. Inclusion criteria were that the participant had to be 18 years or older, fulfil the criteria for MDD according to DSM-IV criteria (APA, 2000) and have a score of five or above on the PHQ-9 (Kroenke et al., 2001). Exclusion criteria were suicide risk, severe psychiatric comorbidity, currently receiving other psychological treatment for depression, insufficient comprehension of the spoken and written Swedish language, and no access to a computer or smartphone with Internet connection. A total of 147 participants were included and 73 of these were randomly allocated to the BCBT group. Only data from the BCBT group is reported, since alliance measures were not collected for the TAU-group.

During the treatment period, that lasted 10 weeks, participants in the BCBTgroup received four face-to-face therapist sessions (week one, three, six, and ten) and 10 online modules. Face-to-face sessions lasted for 45 minutes and modules were delivered in a fixed order. Internet modules were delivered 
through the Swedish Iterapi platform (Vlaescu et al., 2016) and content could be accessed through different devices, such as computer, tablet, or smartphone. Therapists had access to the participant's work with the modules and also supplied new modules, reviewed homework, monitored symptoms of depression, and used secure email to communicate with the participant. All 12 therapists were master students in clinical psychology with previous psychotherapy training in CBT (including internet-based and blended), receiving supervision from a licensed psychotherapist and supervisor during the study period. A treatment manual was provided for the blended treatment to increase treatment fidelity. The treatment included psychoeducation, goal setting, behavioural activation, cognitive restructuring and relapse prevention.

Patient-rated alliance was measured with a translated online version of the WAI-SR (Hatcher \& Gillaspy, 2006), which uses a 5-point Likert-type scale, instead of the 7-point version used in WAI-S. The name Working alliance - short revised - client version (WAI-SR-C) is used here to differentiate from the therapist version also used in the study. The WAI-SR$\mathrm{C}$ was provided at week four of the treatment after participants had received two face-to-face sessions and gained access to three online modules. Cronbach's alpha for WAI-SR-C was $\alpha=.81$ for the Goal subscale, $\alpha=.84$ for the Task subscale, $\alpha=.80$ for the Bond subscale, and $\alpha=.90$ for the composite score. Therapist rated alliance was measured using a translated online version of Working Alliance Inventory - Short Revised - Therapist version (WAI-SR-T; Munder, 2007) that has shown good internal consistency in earlier research, $\alpha=.80$ (Davison, 2008). The WAI-SR-T was provided to therapist at week four, the same time point as the patient version, after the therapist had met with the participants for two face-to-face sessions. Cronbach's alpha for WAI-SR-T was $\alpha=.87$ for the Goal subscale, $\alpha=.88$ for the Task subscale, $\alpha=.78$ for the Bond subscale, and $\alpha=.91$ for the composite score.

As the primary outcome measure, the PHQ-9 (Kroenke et al., 2001) was chosen, a widely-used instrument with good internal consistency, test-retest reliability, and external validity (Blackwell \& McDermott, 2014). PHQ-9 was measured before, after and weekly during the 10 weeks of treatment. 
To analyse continuous outcome data, growth models using multilevel modelling were used. Growth modelling can model individual change rate over time by incorporating random effects, making it useful when examining predictors of individual change (Hesser, 2015). All models used all available data, without imputation being used. In the estimation of parameters (and standard errors), individuals with at least one valid observation on the dependent variable were retained in the model. A restricted maximum likelihood (REML) analysis was used to estimate parameters and the missing at random (MAR) assumption was chosen to handle missing data. The best-fitted model was determined analytically by comparing nested models.

Table 8

Demographic description of the participants

\begin{tabular}{ll}
\hline & $\begin{array}{l}\text { Blended } \\
(\mathrm{n}=73)\end{array}$ \\
\hline $\begin{array}{l}\text { Gender } \\
\text { Female }\end{array}$ & $54(74 \%)$ \\
Age & $34.7(13.9)$ \\
Mean age $(S D)$ & \\
Marital status & \\
Married or & \\
cohabiting & $42(57.5 \%)$ \\
Other & \\
Educational level & $31(42.5 \%)$ \\
University & \\
Other & \\
Employment & $57(78.1 \%)$ \\
Employed & $16(21.9 \%)$ \\
Student & $25(34.2 \%)$ \\
Other & \\
\hline${ }^{\mathrm{d}}$ & $38(52.1 \%)$ \\
& $10(13.7 \%)$ \\
\hline
\end{tabular}

\footnotetext{
${ }^{\mathrm{a}}$ Single, in a relationship but living alone or widow

${ }^{\mathrm{b}}$ Completed or ongoing

${ }^{c}$ Elementary school, upper secondary school or vocational training

${ }^{\mathrm{d}}$ Unemployed, retired or registered sick
} 
Since the main interest was to examine working alliance as a predictor of subsequent changes in depression scores, WAI-SR-C and WAI-SR-T measured at week four, served as predictors in two separate growth model analysis. The weekly PHQ-9 measurements, between week four and postassessment, were used as the dependent variable. To control for symptom reduction on PHQ-9 prior to the measurement of WAI-SR-C and WAI-SRT, week three measurements of PHQ-9 was also added to the analysis as a predictor. To control for therapist differences in outcome a univariate ANOVA with therapist as factor and PHQ-9 at post assessment as dependent variable was calculated.

At pre-treatment, a total of $23.3 \%$ of the participants was on medication for depression (stable), $61.6 \%$ had a comorbid diagnosis and $63 \%$ had an earlier history of psychotherapy. For more information on the participants at pretreatment, see Table 8.

\section{Results and discussion}

Mean ratings for the WAI-SR-C was: total score $(M=3.86, S D=.60)$, Task $(M=3.45, S D=.72)$, Goal $(M=4.04, S D=.70)$ and Bond $(M=4.10, S D=.69)$. Mean ratings for the WAI-SR-T was: total score $(M=3.93, S D=.66)$, Task $(M=3.72, S D=.82)$, Goal $(M=3.57, S D=.93)$ and Bond $(M=4.36, S D=.56)$. There were large and statistically significant intercorrelations between subscales and total score, ranging from $r=.83$ to $r=.87$ for WAI-SR-C and from $r=.76$ to $r=.94$ for WAI-SR-T. No significant differences in PHQ-9 at post-assessment with regard to therapist was found $F(1,11)=1.268$, $p=.270$.

An unconditional model (only time as predictor) showed an average weekly decrease of 0.11 points on PHQ-9, 95\% CI [-0.27, -0.05], from week four to post-measurement. When WAI-SR-C was added in a conditional model no significant effect for WAI-SR-C on change rate for depression was found, but in a conditional model where WAI-SR-T was added a significant effect on change rate for depression was found, $-0.50,95 \%$ CI $[-0.74,-0.26]$. This result indicates that a one-point increase on WAI-SR-T is associated with a 
0.50 decrease on PHQ-9 per week, meaning that higher alliance (rated by therapists) can predict a positive change in depression symptoms during treatment.

The main findings in this study were that the therapist-rated alliance predicts changes in depression and that alliance ratings were high for both therapistand patient measurements. High alliance for blended treatment is in line with research on clinician-guided ICBT (Berger, 2017) and face-to-face CBT (Haug et al., 2016). Patient rated level of depression at the time-point of alliance measures did not affect the predictive ability of WAI and similar results have been seen in other studies controlling for symptom improvement in depression (Falkenström, Granström, \& Holmqvist, 2014).

That therapist-rated, and not patient-rated, alliance correlated with rate of change in depression is an interesting finding. One explanation for this might be that the therapist-rated alliance better reflects the actual relation between therapist and patient, whereas the patient-rated alliance is influenced by the use of added online content. Using a more adapted version of the WAI that takes into consideration the relation to the self-help material, as have been done in other studies on internet-based treatment (Berger, Boettcher, \& Caspar, 2014), might have resulted in different findings.

In this study, an a-priori choice was made to use WAI-SR total score as the main predictor and not use the separate subscale in the main analysis. As WAI-SR have been proposed as measuring three separate subscales this might limit the results, even though a general alliance score is the most common way of measuring working alliance. Also, intercorrelations between WAI-subscales and total score were high.

Not much is known about the psychometric properties of WAI-SR-T, which is a limitation of the study. This limitation has to been seen in the light of earlier research showing that different alliance questionnaires correlate significantly with each other (Martin et al., 2000) and that their relation to outcome is similar (Horvath et al., 2011). 
The study contributes to the knowledge base regarding the role of alliance in blended treatment, as rated by therapists and patients. Results suggest that alliance ratings in blended treatment are similar to those in face-to-face therapies and in internet-based treatments. Also, it seems that the therapistrated alliance could be even more important in predicting symptom change in depression during blended treatment. 


\section{General discussion}

\section{Main findings}

The overall aim of this thesis was to examine the role of therapeutic alliance and the effects of different treatment formats in internet-based CBT for depression (email therapy, two versions of guided self-help and blended treatment). An email therapy manual, created for Study I, was proven effective in the treatment of depression compared to a waiting list condition. There were tendencies that email therapy was more effective than guided self-help at post-treatment with larger effect sizes on the main outcome. However, these differences were not statistically significant. Effects were sustained at six-month follow up, with more than half the participants reaching clinically significant improvement and $96 \%$ of those in the email group no longer fulfilling the criteria for MDD. Positive symptom changes for depression in the waiting list condition influenced the results. One explanation for this could be the thorough pre-treatment procedure that included a diagnostic interview and also two memory tests (Andersson, Sarkohi, Karlsson, Bjärehed, \& Hesser, 2012b; Sarkohi, Bjärehed, \& Andersson, 2011). On the other hand, spontaneous improvement is regularly seen for control groups in psychotherapy studies on depression (Rutherford et al., 2012).

Therapeutic alliance was rated as highly positive in both groups, which was also the case for internet-based treatment focused on generalized anxiety disorder and social anxiety disorder. This is in line with recent research, showing that alliance ratings are high in internet-based treatment (Hadjistavropoulos, Pugh, Hesser, \& Andersson, 2016) and not lower than face-to-face ratings (Stiles-Shields, Kwasny, Cai, \& Mohr, 2014). Scores on the WAI could not predict outcome in any of the three studies included in Paper II. This is different from findings in face-to-face therapy. In a recent narrative review of alliance in Internet interventions (also including video conferencing and chat) the author concludes that results regarding prediction of outcome in internet-based treatment are somewhat inconclusive so far (Berger, 2017). Another finding was that there was a significant difference between the email- and self-help group on the Goal subscale. This might be 
a consequence of less time and a more unclear definition of goals in the selfhelp program compared to the email therapy, as Goal setting was more explicitly addressed early on in the email therapy.

A more interactive self-help program based on behavioural activation with ACT-components was tested in Study III, showing that this way of delivery can be effective for depression. Effects on the main outcome measure were comparable to similar earlier studies on internet-based treatment for depression in Sweden (Andersson et al., 2005) and comparable to face-toface results for behavioural activation (Cuijpers et al., 2007) and CBT (Cuijpers et al., 2013a). On the other hand, measures of clinical significance were relatively low and there was no effect on quality of life. It seems that different versions of CBT and ACT-interventions can be suitable for online delivery, which has also been confirmed by the testing of even more ACToriented online programs (Ivanova et al., 2016; Lappalainen et al., 2014). Another finding was that internet-based treatment was effective even for those with persistent depressed mood, as there were no significant differences regarding change in depression between participants that fulfilled the criteria for dysthymia and those that did not.

Paper IV examined the role of alliance and its ability to predict rate of change in blended treatment for adults with depression. Alliance measures were high and comparable to those in face-to-face CBT (Munder et al., 2010). Analyses of data using growth models showed that therapist-rated alliance, and not patient-rated alliance, predicted change in depression scores during treatment. This is an interesting and somewhat confusing finding as another study from the same research group found that patientrated alliance predicted outcome in blended treatment, but not in face-toface treatment (Ly et al., 2015). It could be that therapist ratings are more important in blended treatment, which opens up for the opportunity to use alliance ratings in regular care to predict change in symptoms during treatment.

Email therapy and the two different formats of guided self-help showed large and significant treatment effects on the main outcome of depression when compared to a waiting list condition. Positive trends were also seen 
for quality of life, but results were non-significant. Even though metaanalyses have shown that treatment for depression can have small to moderate effects on quality of life measures, individual studies often struggle with non-significant results (Kolovos et al., 2016). In addition, only a smaller percentage of participants were defined as reaching clinically relevant improvement in Study III. This can indicate that the treatment, albeit effective in reducing symptoms of depression and anxiety, did not succeed when it comes to reaching a state of remission for enough participants compared to what is expected in treatments for depression (Saragoussi et al., 2017). However, the lack of consensus regarding how to best measure clinically relevant change make it more difficult to compare these results with other studies.

Only $28 \%$ of the participants in Study III completed all modules and the mean number of modules completed was five out of seven. One reason for this could be that the period from pre- to post measurement was too short compared to the time needed to complete the treatment. This was confirmed when asking participants to describe what they thought was the most negative aspects of treatment, as several participants complained about the lack of time. When tested in regular care and allowing patients 12 weeks for completion for the same self-help program, 56\% completed all modules in time (Kivi et al., 2014).

This thesis has some specific strengths worth mentioning. First, all outcome studies were randomized controlled studies, considered the gold standard for clinical research (Meldrum, 2000). Another strength is the use of a diagnostic procedure in all studies, making sure that all included patients fulfilled the criteria for MDD. This increases the external validity of the findings, making sure that the sample treated in these studies are the same as the population health professionals are supposed to treat in regular health care. A third strength is the low dropout rates for Study I and III, where only $3 \%$ did not provide post-measurement data. 


\section{Limitations}

Paper II and IV analysed the predictive validity of WAI on measurements of depression. It can be argued that sample sizes in these studies were too small, and that the studies therefore are underpowered, as limited samples make it difficult to find smaller effects. When combining all three data sets $(n=176)$ in Paper II, a small but non-significant correlation $(r=.06)$ was found between patient-rated alliance and depression.

Measures of alliance were only collected at one point in time, so there was no control for temporal confounds. Other ways of measuring alliance would have been to control for expected alliance (Bergman Nordgren et al., 2013) or to supply the questionnaire weekly to be able to analyse how allianceand depression ratings change over time (Falkenström et al., 2016). Using weekly measurements would also have made it possible to see how therapeutic alliance related to change in depression during the early stages of treatment. This would have been preferable in Paper IV, since changes in depression pre-measurement to week three were large and significant, but changes in depression between week four and post-measurement were smaller and not significant.

Many participants in the studies were highly educated. This might have affected the results since CBT has been found to be more effective for university students (Cuijpers, Ebert, Acarturk, Andersson, \& Cristea, 2016b) and specific studies on internet-based treatment have shown that individuals with a university degree receive better outcomes (Warmerdam, van Straten, Twisk, \& Cuijpers, 2013). It could be a problem for dissemination into regular health care, since ICBT might only fit a small well-educated group of patients. However, when controlling for educational level in Paper I, no significant correlation was found between educational level and change in depression.

Recruitment for Study I and III was done online from the general public and not in regular care settings. It might be that this limits external validity, since the sample includes individuals that are actively seeking ICBT and are motivated enough to sign up for a treatment study. However, there are 
preliminary data showing that the guided self-help program used in Paper III is at least as effective as treatment as usual (face-to-face psychotherapy, antidepressants and/or contact with general practitioner) in a primary care setting (Eriksson et al., 2017). In addition, a recent comparison between recruitment strategies for research studies (e.g. Google, social media, newspaper and clinical settings) showed that there were no significant differences in depression scores between samples recruited through clinical settings and those recruited through Google (Lindner, Nyström, Hassmén, Andersson, \& Carlbring, 2015). This interesting finding indicates that patient characteristics in clinical recruitment might be more similar to those recruited online than expected.

Relapse in depression usually occurs within six to nine months after remission (Hollon et al., 2002). Data was collected using interviews and questionnaires three months after post-treatment measurements in Study III, and six months after post-treatment measurements in Study I. For ethical reasons both control groups received treatment after eight weeks in the waiting list condition. The short time period from post-measurement to follow up, and lack of control condition at that time, makes it harder to draw conclusions about the long-term effects of these treatments. However, a separate three-and-a-half-year follow-up showed that treatment effects were sustained on both main and secondary outcomes for participants in Study I (Andersson, Hesser, Hummerdal, Bergman Nordgren, \& Carlbring, 2013a).

\section{Conclusions and future directions}

It might not be surprising that all interventions in this thesis show positive results in the treatment of depression. It is in line with earlier research on depression, showing that most form psychotherapy and ways of delivery seem to be effective (Cuijpers et al., 2013a). Even so, these three different formats can all be excellent ways of increasing access to effective care for patients.

Secure email can be used in an individualized and easily administered way that minimizes efforts associated with start-up and provides flexibility for the patient and therapist. The possibility to examine the therapist-patient 
interaction more closely also opens up for new possibilities. Written communication is by default saved and thereby open for ongoing and retrospective analyses. This can create opportunities to examine the content of the therapeutic conversation more thoroughly during treatment and find specific behaviours that can explain adherence and outcome in therapy (Schneider et al., 2016).

Guided internet-based self-help can be used to facilitate the delivery of evidence-based treatment programs in a time-effective and large-scale way, without losing quality, and make the wide spread access to psychological treatment much easier. Self-help programs can help therapists overcome uncertainties regarding their own skills and minimize the risk for therapist drift (Waller, 2009). Treatment programs for a range of different diagnoses and psychological problems can be used as tools for a variety of health care professionals to provide effective treatment. And from a patient perspective, psychotherapy has never been more transparent, making it an alternative for the new generation of patients that demand insight into their own care.

Blended treatment can help patients, therapists and stakeholders overcome negative conceptions associated with integrating digital tools into psychotherapy, as many patients still wish to keep some aspect of face-toface contact (Holst et al., 2017). The flexibility of providing parts of the treatment content online, gives therapist several pathways to utilise when working with patients. Some parts of treatment could be better off as selfhelp material, whereas the face-to-face meeting opens up for individualization and keeping traditional aspects of therapy alive. And defined in broader terms, including sequential delivery of face-to-face and online material, it can be used as relapse prevention with positive results (Holländare et al., 2013).

These three internet-based treatment formats can broaden the range of options available for patients struggling with depression. But when creating more options, we also need to know more about who is eligible and benefits from these different alternatives. One example of providing an assessment tool for therapists is the Fit for blended care decision-making instrument, created by researchers at the Center for eHealth and Wellbeing research in the Netherlands (Wentzel, van der Vaart, Bohlmeijer, \& Van Gemert- 
Pijnen, 2016). This instrument is based on the preconditions that need to be met to start blended treatment, which possible barriers may hinder treatment and which facilitating factors that are present. It also includes a discussion material regarding barrier and facilitators that could help patient and therapist make decisions regarding the composition of the blended treatment. Tools like these can help therapists, together with their patients, to choose the right treatment option for the specific individual.

Online self-help programs are usually developed to be used in a set order, for a specified time period. Not completing all modules equals not taking part of the treatment material defined as necessary for success. Adherence to treatment (defined as completing $100 \%$ of treatment) is actually higher in face-to-face CBT compared to internet-based CBT, but for non-completers the adherence to treatment is significantly higher in internet-based treatment (van Ballegooijen et al., 2014). This can be seen in Study III, as full completion was low, but $83 \%$ completed at least four modules. The role of adherence is yet to be understood and a variety of definitions make it harder to compare and discuss these issues. Creating programs that increase adherence and hopefully effects of treatment could be a key issue in the development of new internet interventions up ahead. Study III used a more interactive web-based solution, aimed to increase motivation and adherence. Adherence was not improved compared to Study I, although no specific analyses were made on the role of technology and its effects on platform usage. The most probable reason for low completion rates was the short time period between pre- and post-measurement. Some participants had as low as seven weeks to complete the program, which originally was intended to be used over 10 weeks. There is still a lot to be learned regarding how we best use technology to provide therapy and some researchers have used a more theory-based approach when developing digital solutions that contains therapeutic interventions (Kelders, Pots, Oskam, Bohlmeijer, \& Van Gemert-Pijnen, 2013; Short, Rebar, \& Plotnikoff, 2015). The use of smartphones and mobile technology in internet-based interventions is also a growing research field. Specific studies have shown that internet-based self-help programs are equally effective when delivered through a mobile phone (Watts et al., 2013). The addition of mobile technology also has the possibility to enhance face-to-face interventions, thereby being an 
alternative when delivering blended treatment (Lindhiem, Bennett, Rosen, \& Silk, 2015).

The role of therapeutic alliance in internet-based treatment continue to be an interesting question for future research. It might be that there are different aspects of alliance that are important in ICBT compared to face-to-face CBT (Jasper et al., 2014) and the development of specific questionnaires can be a way to capture the unique aspects of this treatment format. Adaptations in wording to better suit the internet-based treatment format were made in the versions of WAI used in this thesis. Other researchers have gone one step further and created questionnaires that specifically ask patients to rate certain aspects of alliance (Task and Bond) in relation to the self-help program (Berger et al., 2014). This development of new patient-rated alliance measures to be used in internet-based treatment is based on the fact that the main part of treatment is provided in the form of self-help material online, and not by the therapist. Which makes it important to know if patients are experiencing alliance towards the therapist, the self-help material, or both. For therapist rated alliance in internet-based treatment, the ratings are still based on the communication between therapist and patient. This might make therapist ratings in internet-based treatment more comparable to face-to-face research, which could possibly explain the results in Paper IV. Another interesting finding from other researchers is that a positive therapeutic alliance can be achieved in the absence of therapist support (Clarke et al., 2016). Although patient rated alliance could not predict treatment outcome, similar to the studies in this thesis, ratings of emotional connection with the treatment program was significantly correlated with module completion and number of program logins. These results might not be so surprising. Richardson et al. (2010) found in their analysis of common factors in self-help books for depression that empathy, warmth and genuineness was highly prevalent in two out of the three selfhelp books examined. This puts the notion that the therapeutic relationship is relying on the traditional face-to-face patient and therapist interaction in a whole different light. Questions raised from findings in this thesis, and the above-mentioned studies, can hopefully help us evolve the concept of therapeutic alliance and its role in treatment for depression. 
The program in Study III was based on behavioural activation with ACTcomponents. One could argue that the need for an addition of other functional strategies than those provided in the original model are not necessary, even though there is an evolvement towards the inclusion of more acceptance- and mindfulness based strategies for CBT in general. Just as in the ground-breaking work of Jacobsen et al. (1996) in their dismantling study, the internet-based treatment format might actually help us answer these sorts of questions up ahead. Providing self-help material divided into components that are considered effective in CBT, such as activity scheduling, functional analysis and thought challenging, gives the possibility to do factorial studies and component analyses on a more detailed level (Watkins et al., 2016). These sorts of studies could give insight into the active components, and combination of interventions, in CBT. Moreover, it could shed light on the role of non-specific common factors (such as alliance), and the impact of these versus specific factors in treatment (such as behavioural activation and functional analysis).

Back in 1979 Glasgow and Rosen laid out the future road for implementation and research on bibliotherapy. They suggested a distinction between different formats based on the amount of therapist contact, addressed the issue of attrition and suggested more attention to the research on predictors. They also discussed using factorial designs to decide which components to include in future self-help programs and encouraged the opportunity to develop and disseminate empirically validated methods through using self-help programs. In large, it seems these issues are still relevant and hopefully this thesis has helped to answer some of the questions associated with them. But then again, research often raises more questions it answers.

There is no need to worry that internet-based alternatives will replace therapists and face-to-face psychotherapy. Instead, we need more tools to deliver effective treatment for all those suffering from depression. I see a bright future, creating a new era for psychological interventions, where treatment can be delivered in an effective and transparent way to a much larger population. This is only the beginning. 


\section{References}

Almlöv, J., Carlbring, P., Berger, T., Cuijpers, P., \& Andersson, G. (2009). Therapist factors in Internet-delivered cognitive behavioural therapy for major depressive disorder. Cognitive Behaviour Therapy, 38(4), 247254. http://doi.org/10.1080/16506070903116935

Alonso, J., Angermeyer, M. C., Bernert, S., Bruffaerts, R., Brugha, T. S., Bryson, H., et al. (2004). Disability and quality of life impact of mental disorders in Europe: results from the European Study of the Epidemiology of Mental Disorders (ESEMeD) project. Acta Psychiatrica Scandinavica. Supplementum, 109(420), 38-46. http://doi.org/10.1111/j.1600-0047.2004.00329.x

Alonso, J., Lépine, J.-P., ESEMeD/MHEDEA 2000 Scientific Committee. (2007). Overview of key data from the European Study of the Epidemiology of Mental Disorders (ESEMeD). The Journal of Clinical Psychiatry, 68 Suppl 2, 3-9.

American Psychiatric Association. (2000). Diagnostic and Statistical Manual of Mental Disorders (4th ed., text rev.). American Psychiatric Press, Washington, DC.

American Psychiatric Association. (2013). Diagnostic and Statistical Manual of Mental Disorders (5th ed.). American Psychiatric Press, Wahsington, DC.

Andersson, G. (2009). Using the Internet to provide cognitive behaviour therapy. Behaviour Research and Therapy, 47(3), 175-180. http://doi.org/10.1016/j.brat.2009.01.010

Andersson, G., \& Carlbring, P. (2003). Internet and cognitive behaviour therapy: new opportunities for treatment and assessment. Cognitive Behaviour Therapy, 32(3), 97-99. http://doi.org/10.1080/16506070302315

Andersson, G., \& Cuijpers, P. (2009). Internet-based and other computerized psychological treatments for adult depression: a metaanalysis. Cognitive Behaviour Therapy, 38(4), 196-205. http://doi.org/10.1080/16506070903318960

Andersson, G., \& Hedman, E. (2013). Effectiveness of guided internetbased cognitive behavior therapy in regular clinical settings. Verhaltenstherapie, 23(3), 140-148.

Andersson, G., Bergström, J., Buhrman, M., Carlbring, P., Holländare, F., Kaldo, V., et al. (2008). Development of a New Approach to Guided Self-Help via the Internet: The Swedish Experience. Journal of Technology in Human Services, 26(2-4), 161-181. http://doi.org/10.1080/15228830802094627 
Andersson, G., Bergström, J., Holländare, F., Carlbring, P., Kaldo, V., \& Ekselius, L. (2005). Internet-based self-help for depression: randomised controlled trial. The British Journal of Psychiatry, 187(5), 456-461. http://doi.org/10.1192/bjp.187.5.456

Andersson, G., Carlbring, P., Furmark, T., S. O. F. I. E. Research Group. (2012a). Therapist experience and knowledge acquisition in internetdelivered CBT for social anxiety disorder: a randomized controlled trial. PLoS ONE, 7(5), e37411. http://doi.org/10.1371/journal.pone.0037411

Andersson, G., Cuijpers, P., Carlbring, P., Riper, H., \& Hedman, E. (2014). Guided Internet-based vs. face-to-face cognitive behavior therapy for psychiatric and somatic disorders: A systematic review and metaanalysis. World Psychiatry, 13(3), 288-295.

http://doi.org/10.1002/wps.20151

Andersson, G., Hesser, H., Hummerdal, D., Bergman Nordgren, L., \& Carlbring, P. (2013a). A 3.5-year follow-up of Internet-delivered cognitive behavior therapy for major depression. Journal of Mental Health (Abingdon, England), 22(2), 155-164. http://doi.org/10.3109/09638237.2011.608747

Andersson, G., Hesser, H., Veilord, A., Svedling, L., Andersson, F., Sleman, O., et al. (2013b). Randomised controlled non-inferiority trial with 3-year follow-up of internet-delivered versus face-to-face group cognitive behavioural therapy for depression. Journal of Affective Disorders, 151(3), 986-994. http://doi.org/10.1016/j.jad.2013.08.022

Andersson, G., Sarkohi, A., Karlsson, J., Bjärehed, J., \& Hesser, H. (2012b). Effects of two forms of internet-delivered cognitive behaviour therapy for depression on future thinking. Cognitive Therapy and Research, 37(1), 29-34. http://doi.org/10.1007/s10608-012-9442-y

Andersson, G., Topooco, N., Havik, O., \& Nordgreen, T. (2016). Internetsupported versus face-to-face cognitive behavior therapy for depression. Expert Review of Neurotherapeutics, 16(1), 55-60. http://doi.org/10.1586/14737175.2015.1125783

Andrade, L., Caraveo-Anduaga, J. J., Berglund, P., Bijl, R. V., De Graaf, R., Vollebergh, W., et al. (2003). The epidemiology of major depressive episodes: Results from the International Consortium of Psychiatric Epidemiology (ICPE) Surveys. International Journal of Methods in Psychiatric Research, 12(1), 3-21. http://doi.org/10.1002/mpr.138

Andrews, G., Cuijpers, P., Craske, M. G., McEvoy, P., \& Titov, N. (2010). Computer therapy for the anxiety and depressive disorders is effective, acceptable and practical health care: a meta-analysis. PLoS ONE, 5(10), e13196. http://doi.org/10.1371/journal.pone.0013196

Andrews, G., Henderson, S., \& Hall, W. (2001). Prevalence, comorbidity, disability and service utilisation. Overview of the Australian National 
Mental Health Survey. The British Journal of Psychiatry, 178(2), 145153. http://doi.org/10.1192/bjp.178.2.145

Arnberg, F. K., Linton, S. J., Hultcrantz, M., Heintz, E., \& Jonsson, U. (2014). Internet-delivered psychological treatments for mood and anxiety disorders: a systematic review of their efficacy, safety, and costeffectiveness. PLoS ONE, 9(5), e98118.

http://doi.org/10.1371/journal.pone.0098118

Baker, S. L., Heinrichs, N., Kim, H.-J., \& Hofmann, S. G. (2002). The liebowitz social anxiety scale as a self-report instrument: a preliminary psychometric analysis. Behaviour Research and Therapy, 40(6), 701715.

Barak, A., Klein, B., \& Proudfoot, J. G. (2009). Defining internet-supported therapeutic interventions. Annals of Behavioral Medicine, 38(1), 4-17. http://doi.org/10.1007/s12160-009-9130-7

Barth, J., Munder, T., Gerger, H., Nüesch, E., Trelle, S., Znoj, H., et al. (2013). Comparative efficacy of seven psychotherapeutic interventions for patients with depression: a network meta-analysis. PLoS Medicine, 10(5), e1001454. http://doi.org/10.1371/journal.pmed.1001454

Bauer, M., Severus, E., Möller, H.-J., Young, A. H., WFSBP Task Force on Unipolar Depressive Disorders. (2017). Pharmacological treatment of unipolar depressive disorders: summary of WFSBP guidelines. International Journal of Psychiatry in Clinical Practice, 21(3), 166176. http://doi.org/10.1080/13651501.2017.1306082

Bauer, S., Lambert, M. J., \& Nielsen, S. L. (2004). Clinical significance methods: a comparison of statistical techniques. Journal of Personality Assessment, 82(1), 60-70. http://doi.org/10.1207/s15327752jpa8201_11

Baumeister, H., Reichler, L., Munzinger, M., \& Lin, J. (2014). The impact of guidance on Internet-based mental health interventions - A systematic review. Internet Interventions, 1(4), 205-215. http://doi.org/10.1016/j.invent.2014.08.003

Beck, A. T. (1963). Thinking and depression. I. Idiosyncratic content and cognitive distortions. Archives of General Psychiatry, 9(4), 324-333. http://doi.org/10.1001/archpsyc.1963.01720160014002

Beck, A. T. (1964). Thinking and depression. II. Theory and therapy. Archives of General Psychiatry, 10(6), 561-571. http://doi.org/10.1001/archpsyc.1964.01720240015003

Beck, A. T. (1967). Depression: clinical, experimental, and theoretical aspects. Philadelphia: University of Pennsylvania Press.

Beck, A. T. (2008). The evolution of the cognitive model of depression and its neurobiological correlates. The American Journal of Psychiatry, 165(8), 969-977. http://doi.org/10.1176/appi.ajp.2008.08050721

Beck, A. T., Epstein, N., Brown, G., \& Steer, R. A. (1988a). An inventory 
for measuring clinical anxiety: psychometric properties. Journal of Consulting and Clinical Psychology, 56(6), 893-897.

Beck, A. T., Steer, R. A., \& Brown, G. K. (1996). Manual for the Beck Depression Inventory-II. Psychological corporation, San Antonio, TX.

Beck, A. T., Steer, R. A., \& Garbin, M. G. (1988b). Psychometric properties of the Beck Depression Inventory: twenty five years of evalutation. Clinical Psychology Review, 8, 77-100.

Beck, A. T., Ward, C. H., Mendelson, M., Mock, J., \& Erbaugh, J. (1961). An inventory for measuring depression. Archives of General Psychiatry, $4,561-571$.

Bendelin, N., Hesser, H., Dahl, J., Carlbring, P., Nelson, K., \& Andersson, G. (2011). Experiences of guided Internet-based cognitive-behavioural treatment for depression: A qualitative study. BMC Psychiatry, 11(1), 107. http://doi.org/10.1186/1471-244X-11-107

Berger, T. (2017). The therapeutic alliance in internet interventions: A narrative review and suggestions for future research. Psychotherapy Research, 27(5), 511-524. http://doi.org/10.1080/10503307.2015.1119908

Berger, T., Boettcher, J., \& Caspar, F. (2014). Internet-based guided selfhelp for several anxiety disorders: A randomized controlled trial comparing a tailored with a standardized disorder-specific approach. Psychotherapy, 51(2), 207-219. http://doi.org/10.1037/a0032527

Bergman Nordgren, L., Carlbring, P., Linna, E., \& Andersson, G. (2013). Role of the working alliance on treatment outcome in tailored internetbased cognitive behavioural therapy for anxiety disorders: randomized controlled pilot trial. JMIR Research Protocols, 2(1), e4. http://doi.org/10.2196/resprot.2292

Blackwell, T. L., \& McDermott, A. N. (2014). Test review: Patient Health Questionnaire-9 (PHQ-9). Rehabilitation Counseling Bulletin, 57(4), 246-248. http://doi.org/10.1177/0034355213515305

Boer, den, P. C. A. M., Wiersma, D., \& Van den Bosch, R. J. (2004). Why is self-help neglected in the treatment of emotional disorders? A metaanalysis. Psychological Medicine, 34(6), 959-971. http://doi.org/10.1017/S003329170300179X

Bordin, E. S. (1979). The generalizability of the psychoanalytic concept of the working alliance. Psychotherapy, 16(3), 252-260. http://doi.org/10.1037/h0085885

Burns, M. D. (1999). Feeling Good. New York: Harper Collins.

Busseri, M. A., \& Tyler, J. D. (2003). Interchangeability of the Working Alliance Inventory and Working Alliance Inventory, Short Form. Psychological Assessment, 15(2), 193-197. http://doi.org/10.1037/10403590.15.2.193 
Carlbring, P., Brunt, S., Bohman, S., Austin, D., Richards, J., Öst, L. G., \& Andersson, G. (2007). Internet vs. paper and pencil administration of questionnaires commonly used in panic/agoraphobia research.

Computers in Human Behavior, 23(3), 1421-1434.

http://doi.org/10.1016/j.chb.2005.05.002

Carlbring, P., Furmark, T., Steczkó, J., Ekselius, L., \& Andersson, G. (2011). An open study of Internet-based bibliotherapy with minimal therapist contact via email for social phobia. Clinical Psychologist, 10(1), 30-38. http://doi.org/10.1080/13284200500378662

Catty, J. (2004). "The vehicle of success": theoretical and empirical perspectives on the therapeutic alliance in psychotherapy and psychiatry. Psychology and Psychotherapy, 77(Pt 2), 255-272. http://doi.org/10.1348/147608304323112528

Chester, A., \& Glass, C. A. (2006). Online counselling: a descriptive analysis of therapy services on the Internet. British Journal of Guidance and Counselling, 34(2), 145-160. http://doi.org/10.1080/03069880600583170

Clarke, J., Proudfoot, J., Whitton, A., Birch, M.-R., Boyd, M., Parker, G., et al. (2016). Therapeutic alliance with a fully automated mobile phone and web-based intervention: secondary analysis of a randomized controlled trial. JMIR Mental Health, 3(1), e10. http://doi.org/10.2196/mental.4656

Cohen, J. (1988). Statistical Power Analysis for the Behavioral Sciences. Lawrence Erlbaum Associates, New Jersey.

Cook, J. E., \& Doyle, C. (2002). Working alliance in online therapy as compared to face-to-face therapy: preliminary results. CyberPsychology \& Behavior, 5(2), 95-105. http://doi.org/10.1089/109493102753770480

Cuijpers, P. (1997). Bibliotherapy in unipolar depression: a meta-analysis. Journal of Behavior Therapy and Experimental Psychiatry, 28(2), 139147.

Cuijpers, P. (1998). A psychoeducational approach to the treatment of depression: a meta-analysis of Lewinsohn's 'Coping with Depression' course. Behavior Therapy, 29(3), 521-533. http://doi.org/10.1016/S0005-7894(98)80047-6

Cuijpers, P. (2015). Psychotherapies for adult depression: Recent developments. Current Opinion in Psychiatry, 28(1), 24-29. http://doi.org/10.1097/YCO.0000000000000121

Cuijpers, P. (2016). Are all psychotherapies equally effective in the treatment of adult depression? The lack of statistical power of comparative outcome studies. Evidence-Based Mental Health, 19(2), 39-42. http://doi.org/10.1136/eb-2016-102341

Cuijpers, P., Berking, M., Andersson, G., Quigley, L., Kleiboer, A., \& 
Dobson, K. S. (2013a). A meta-analysis of cognitive-behavioural therapy for adult depression, alone and in comparison with other treatments. Canadian Journal of Psychiatry. Revue Canadienne De Psychiatrie, 58(7), 376-385. http://doi.org/10.1177/070674371305800702

Cuijpers, P., Cristea, I. A., Karyotaki, E., Reijnders, M., \& Huibers, M. J. H. (2016a). How effective are cognitive behavior therapies for major depression and anxiety disorders? A meta-analytic update of the evidence. World Psychiatry, 15(3), 245-258. http://doi.org/10.1002/wps.20346

Cuijpers, P., Donker, T., van Straten, A., Li, J., \& Andersson, G. (2010a). Is guided self-help as effective as face-to-face psychotherapy for depression and anxiety disorders? A systematic review and metaanalysis of comparative outcome studies. Psychological Medicine, 40(12), 1943-1957. http://doi.org/10.1017/S0033291710000772

Cuijpers, P., Ebert, D. D., Acarturk, C., Andersson, G., \& Cristea, I. A. (2016b). Personalized psychotherapy for adult depression: a metaanalytic review. Behavior Therapy, 47(6), 966-980. http://doi.org/10.1016/j.beth.2016.04.007

Cuijpers, P., Huibers, M., Ebert, D. D., Koole, S. L., \& Andersson, G. (2013b). How much psychotherapy is needed to treat depression? A metaregression analysis. Journal of Affective Disorders, 149(1-3), 1-13. http://doi.org/10.1016/j.jad.2013.02.030

Cuijpers, P., Kleiboer, A., Karyotaki, E., \& Riper, H. (2017). Internet and mobile interventions for depression: Opportunities and challenges. Depression and Anxiety, 34(7), 596-602. http://doi.org/10.1002/da.22641

Cuijpers, P., van Straten, A., \& Andersson, G. (2008). Internet-administered cognitive behavior therapy for health problems: a systematic review. Journal of Behavioral Medicine, 31(2), 169-177. http://doi.org/10.1007/s10865-007-9144-1

Cuijpers, P., van Straten, A., \& Warmerdam, L. (2007). Behavioral activation treatments of depression: a meta-analysis. Clinical Psychology Review, 27(3), 318-326. http://doi.org/10.1016/j.cpr.2006.11.001

Cuijpers, P., van Straten, A., Schuurmans, J., Van Oppen, P., Hollon, S. D., \& Andersson, G. (2010b). Psychotherapy for chronic major depression and dysthymia: a meta-analysis. Clinical Psychology Review, 30(1), 5162. http://doi.org/10.1016/j.cpr.2009.09.003

Davison, L. L. (2008). Embodying the therapeutic alliance: an exploration of the working alliance in the personal trainer-client relationship. Theses, Dissertations, and Projects. Paper 1227. 
Dimidjian, S., Barrera, M., Martell, C., Muñoz, R. F., \& Lewinsohn, P. M. (2011). The origins and current status of behavioral activation treatments for depression. Annual Review of Clinical Psychology, 7(1), 1-38. http://doi.org/10.1146/annurev-clinpsy-032210-104535

Dimidjian, S., Hollon, S. D., Dobson, K. S., Schmaling, K. B., Kohlenberg, R. J., Addis, M. E., et al. (2006). Randomized trial of behavioral activation, cognitive therapy, and antidepressant medication in the acute treatment of adults with major depression. Journal of Consulting and Clinical Psychology, 74(4), 658-670. http://doi.org/10.1037/0022006X.74.4.658

Donker, T., Bennett, K., Bennett, A., Mackinnon, A., van Straten, A., Cuijpers, P., et al. (2013). Internet-delivered interpersonal psychotherapy versus internet-delivered cognitive behavioral therapy for adults with depressive symptoms: randomized controlled noninferiority trial. Journal of Medical Internet Research, 15(5), e8216. http://doi.org/10.2196/jmir.2307

Driessen, E., Cuijpers, P., Hollon, S. D., \& Dekker, J. J. M. (2010). Does pretreatment severity moderate the efficacy of psychological treatment of adult outpatient depression? A meta-analysis. Journal of Consulting and Clinical Psychology, 78(5), 668-680. http://doi.org/10.1037/a0020570

Ebmeier, K. P., Donaghey, C., \& Steele, J. D. (2006). Recent developments and current controversies in depression. The Lancet, 367, 153-167. http://doi.org/10.1016/S0140-6736(06)67964-6

Ekers, D., Webster, L., van Straten, A., Cuijpers, P., Richards, D., \& Gilbody, S. (2014). Behavioural activation for depression; an update of meta-analysis of effectiveness and sub group analysis. PLoS ONE, 9(6), e100100. http://doi.org/10.1371/journal.pone.0100100

Elvins, R., \& Green, J. (2008). The conceptualization and measurement of therapeutic alliance: an empirical review. Clinical Psychology Review, 28(7), 1167-1187. http://doi.org/10.1016/j.cpr.2008.04.002

Emmelkamp, P. M. G., David, D., Beckers, T., Muris, P., Cuijpers, P., Lutz, W., et al. (2014). Advancing psychotherapy and evidence-based psychological interventions. International Journal of Methods in Psychiatric Research, 23 Suppl 1(S1), 58-91.

http://doi.org/10.1002/mpr.1411

Erbe, D., Eichert, H.-C., Riper, H., \& Ebert, D. D. (2017). Blending face-toface and internet-based interventions for the treatment of mental disorders in adults: systematic review. Journal of Medical Internet Research, 19(9), e306-16. http://doi.org/10.2196/jmir.6588

Eriksson, M. C. M., Kivi, M., Hange, D., Petersson, E.-L., Ariai, N., Häggblad, P., et al. (2017). Long-term effects of Internet-delivered 
cognitive behavioral therapy for depression in primary care - the PRIMNET controlled trial. Scandinavian Journal of Primary Health Care, 35(2), 126-136. http://doi.org/10.1080/02813432.2017.1333299

Eysenbach, G. (2005). The Law of Attrition. Journal of Medical Internet Research, 7(1), e11-9. http://doi.org/10.2196/jmir.7.1.e11

Falkenström, F., Ekeblad, A., \& Holmqvist, R. (2016). Improvement of the working alliance in one treatment session predicts improvement of depressive symptoms by the next session. Journal of Consulting and Clinical Psychology, 84(8), 738-751. http://doi.org/10.1037/ccp0000119

Falkenström, F., Granström, F., \& Holmqvist, R. (2014). Working alliance predicts psychotherapy outcome even while controlling for prior symptom improvement. Psychotherapy Research, 24(2), 146-159. http://doi.org/10.1080/10503307.2013.847985

Falkenström, F., Hatcher, R. L., \& Holmqvist, R. (2015). Confirmatory Factor Analysis of the Patient Version of the Working Alliance Inventory--Short Form Revised. Assessment, 22(5), 581-593. http://doi.org/10.1177/1073191114552472

Ferrari, A. J., Somerville, A. J., Baxter, A. J., Norman, R., Patten, S. B., Vos, T., \& Whiteford, H. A. (2013). Global variation in the prevalence and incidence of major depressive disorder: a systematic review of the epidemiological literature. Psychological Medicine, 43(3), 471-481. http://doi.org/10.1017/S0033291712001511

First, M. B., Spitzer, R. L., Williams, J. B., \& Gibbon, M. (1997). Structured Clinical Interview for DSM-IV Axis I Disorders (SCID-I), Clinician Version. American Psychiatric Press, Washington, DC.

Frisch, M. B., Cornell, J., Villanueva, M., \& Retzlaff, P. J. (1992). Clinical Validation of the Quality of Life Inventory: A Measure of Life Satisfaction for Use in Treatment Planning and Outcome Assessment. Psychological Assessment, 4(1), 92-101.

Furmark, T., Carlbring, P., Hedman, E., Sonnenstein, A., Clevberger, P., Bohman, B., et al. (2009). Guided and unguided self-help for social anxiety disorder: randomised controlled trial. The British Journal of Psychiatry, 195(5), 440-447. http://doi.org/10.1192/bjp.bp.108.060996

Glasgow, R. E., \& Rosen, G. M. (1978). Behavioral bibliotherapy: a review of self-help behavior therapy manuals. Psychological Bulletin, 85(1), 123. http://doi.org/10.1037/0033-2909.85.1.1

Gould, R. A., \& Clum, G. A. (1993). A meta-analysis of self-help treatment approaches. Clinical Psychology Review, 13(2), 169-186. http://doi.org/10.1016/0272-7358(93)90039-O

Gregory, R. J., Schwer Canning, S., Lee, T. W., \& Wise, J. C. (2004). Cognitive Bibliotherapy for Depression: A Meta-Analysis. Professional 
Psychology: Research and Practice, 35(3), 275-280.

http://doi.org/10.1037/0735-7028.35.3.275

Griffiths, M. (2001, April 11). Online therapy: a cause for concern? The Psychologist, 1-6.

Guy, W. (1976). Clinical global impressions. In. ECDEU manual, US Dept of health and human services (pp.217-222). Rockville, MD:NIMH.

Hadjistavropoulos, H. D., Pugh, N. E., Hesser, H., \& Andersson, G. (2016). Therapeutic alliance in internet-delivered cognitive behaviour therapy for depression or generalized anxiety. Clinical Psychology \& Psychotherapy, 24(2), 451-461. http://doi.org/10.1002/cpp.2014

Hatcher, R. L., \& Gillaspy, J. A. (2006). Development and validation of a revised short version of the Working Alliance Inventory. Psychotherapy Research, 16(1), 12-25. http://doi.org/10.1080/10503300500352500

Haug, T., Nordgreen, T., Öst, L. G., Tangen, T., Kvale, G., Hovland, O. J., et al. (2016). Working alliance and competence as predictors of outcome in cognitive behavioral therapy for social anxiety and panic disorder in adults. Behaviour Research and Therapy, 77(C), 40-51. http://doi.org/10.1016/j.brat.2015.12.004

Hayes, S. C., Strosahl, K. D., \& Wilson, K. G. (2012). Acceptance and Commitment Therapy, Second Edition. New York: Guilford Press.

Hedman, E., Ljótsson, B., \& Lindefors, N. (2012). Cognitive behavior therapy via the Internet: A systematic review of applications, clinical efficacy and cost-effectiveness. Expert Review of Pharmacoeconomics \& Outcomes Research, 12(6), 745-764. http://doi.org/10.1586/erp.12.67

Hedman, E., Ljótsson, B., Kaldo, V., Hesser, H., Alaoui, El, S., Kraepelien, M., et al. (2014). Effectiveness of Internet-based cognitive behaviour therapy for depression in routine psychiatric care. Journal of Affective Disorders, 155(1), 49-58. http://doi.org/10.1016/j.jad.2013.10.023

Hedman, E., Ljótsson, B., Ruck, C., Furmark, T., Carlbring, P., Lindefors, N., \& Andersson, G. (2010). Internet administration of self-report measures commonly used in research on social anxiety disorder: A psychometric evaluation. Computers in Human Behavior, 26(4), 736740. http://doi.org/10.1016/j.chb.2010.01.010

Helgadóttir, F. D., Menzies, R. G., Packman, A., \& O'Brian, S. (2009). Online CBT I: Bridging the gap between Eliza and modern online CBT treatment packages. Behaviour Change, 1-10.

Hesser, H. (2015). Modeling individual differences in randomized experiments using growth models: Recommendations for design, statistical analysis and reporting of results of internet interventions. Internet Interventions, 2(2), 110-120. http://doi.org/10.1016/j.invent.2015.02.003 
Hesser, H., Weise, C., Westin, V. Z., \& Andersson, G. (2011). A systematic review and meta-analysis of randomized controlled trials of cognitivebehavioral therapy for tinnitus distress. Clinical Psychology Review, 31(4), 545-553. http://doi.org/10.1016/j.cpr.2010.12.006

Hilvert-Bruce, Z., Rossouw, P. J., Wong, N., Sunderland, M., \& Andrews, G. (2012). Adherence as a determinant of effectiveness of internet cognitive behavioural therapy for anxiety and depressive disorders. Behaviour Research and Therapy, 50(7-8), 463-468. http://doi.org/10.1016/j.brat.2012.04.001

Holländare, F., Andersson, G., \& Engström, I. (2010). A comparison of psychometric properties between internet and paper versions of two depression instruments (BDI-II and MADRS-S) administered to clinic patients. Journal of Medical Internet Research, 12(5), e49. http://doi.org/10.2196/jmir.1392

Holländare, F., Anthony, S. A., Randestad, M., Tillfors, M., Carlbring, P., Andersson, G., \& Engström, I. (2013). Two-year outcome of internetbased relapse prevention for partially remitted depression. Behaviour Research and Therapy, 51(11), 719-722. http://doi.org/10.1016/j.brat.2013.08.002

Holländare, F., Gustafsson, S. A., Berglind, M., Grape, F., Carlbring, P., Andersson, G., et al. (2016). Therapist behaviours in internet-based cognitive behaviour therapy (ICBT) for depressive symptoms. Internet Interventions, 3, 1-7. http://doi.org/10.1016/j.invent.2015.11.002

Hollon, S. D., \& Ponniah, K. (2010). A review of empirically supported psychological therapies for mood disorders in adults. Depression and Anxiety, 27(10), 891-932. http://doi.org/10.1002/da.20741

Hollon, S. D., Muñoz, R. F., Barlow, D. H., Beardslee, W. R., Bell, C. C., Bernal, G., et al. (2002). Psychosocial intervention development for the prevention and treatment of depression: promoting innovation and increasing access. Biological Psychiatry, 52(6), 610-630.

Holst, A., Nejati, S., Björkelund, C., Eriksson, M. C. M., Hange, D., Kivi, M., et al. (2017). Patients' experiences of a computerised self-help program for treating depression - a qualitative study of Internet mediated cognitive behavioural therapy in primary care. Scandinavian Journal of Primary Health Care, 35(1), 46-53. http://doi.org/10.1080/02813432.2017.1288813

Horvath, A. O., \& Greenberg, L. S. (1989). Development and validation of the Working Alliance Inventory. Journal of Counseling Psychology, 36(2), 223-233.

Horvath, A. O., \& Symonds, B. D. (1991). Relation between working alliance and outcome in psychotherapy: A meta-analysis. Journal of Counseling Psychology, 38(2), 139-149. http://doi.org/10.1037/0022- 
0167.38.2.139

Horvath, A. O., Del Re, A. C., Flückiger, C., \& Symonds, D. (2011).

Alliance in individual psychotherapy. Psychotherapy, 48(1), 9-16.

http://doi.org/10.1037/a0022186

Houghton, S., Curran, J., \& Saxon, D. (2008). An Uncontrolled Evaluation of Group Behavioural Activation for Depression. Behavioural and Cognitive Psychotherapy, 36(02), 1-5.

http://doi.org/10.1017/S1352465808004207

Høifødt, R. S., Lillevoll, K. R., Griffiths, K. M., Wilsgaard, T., Eisemann, M., Waterloo, K., \& Kolstrup, N. (2013). The clinical effectiveness of web-based cognitive behavioral therapy with face-to-face therapist support for depressed primary care patients: randomized controlled trial. Journal of Medical Internet Research, 15(8), e153-22. http://doi.org/10.2196/jmir.2714

Internetstiftelsen i Sverige. (2016). Svenskarna och internet 2016 undersökning om svenskarnas internetvanor. Stockholm: Internetstiftelsen i Sverige (IIS)

Ivanova, E., Lindner, P., Ly, K. H., Dahlin, M., Vernmark, K., Andersson, G., \& Carlbring, P. (2016). Guided and unguided Acceptance and Commitment Therapy for social anxiety disorder and/or panic disorder provided via the Internet and a smartphone application: A randomized controlled trial. Journal of Anxiety Disorders, 44, 27-35. http://doi.org/10.1016/j.janxdis.2016.09.012

Jacobson, N. S., \& Truax, P. (1991). Clinical significance: a statistical approach to defining meaningful change in psychotherapy research. Journal of Consulting and Clinical Psychology, 59(1), 12-19.

Jacobson, N. S., Dobson, K. S., Truax, P. A., Addis, M. E., Koerner, K., Gollan, J. K., et al. (1996). A component analysis of cognitivebehavioral treatment for depression. Journal of Consulting and Clinical Psychology, 64(2), 295-304.

Jasper, K., Weise, C., Conrad, I., Andersson, G., Hiller, W., \& Kleinstäuber, M. (2014). The working alliance in a randomized controlled trial comparing Internet-based self-help and face-to-face cognitive behavior therapy for chronic tinnitus. Internet Interventions, 1(2), 49-57. http://doi.org/10.1016/j.invent.2014.04.002

Johansson, R., \& Andersson, G. (2012). Internet-based psychological treatments for depression. Expert Review of Neurotherapeutics, 12(7), 861-870. http://doi.org/10.1586/ern.12.63

Johansson, R., Björklund, M., Hornborg, C., Karlsson, S., Hesser, H., Ljótsson, B., et al. (2013a). Affect-focused psychodynamic psychotherapy for depression and anxiety through the Internet: a randomized controlled trial. PeerJ, 1, e102. 
http://doi.org/10.7717/peerj.102

Johansson, R., Carlbring, P., Heedman, Å., Paxling, B., \& Andersson, G. (2013b). Depression, anxiety and their comorbidity in the Swedish general population: point prevalence and the effect on health-related quality of life. PeerJ, 1, e98. http://doi.org/10.7717/peerj.98

Johansson, R., Sjöberg, E., Sjögren, M., Johnsson, E., Carlbring, P., Andersson, T., et al. (2012). Tailored vs. standardized internet-based cognitive behavior therapy for depression and comorbid symptoms: a randomized controlled trial. PLOS ONE, 7(5), e36905. http://doi.org/10.1371/journal.pone.0036905

Karyotaki, E., Kleiboer, A., Smit, F., Turner, D. T., Pastor, A. M., Andersson, G., et al. (2015). Predictors of treatment dropout in selfguided web-based interventions for depression: an "individual patient data" meta-analysis. Psychological Medicine, 45(13), 2717-2726. http://doi.org/10.1017/S0033291715000665

Keeley, H., Williams, C., \& Shapiro, D. A. (2002). A United Kingdom survey of accredited cognitive behaviour therapists' attitudes toward and use of structured self-help materials. Behavioural and Cognitive Psychotherapy, 30, 193-203. http://doi.org/10.1017/S1352465802002060

Kelders, S. M., Kok, R. N., Ossebaard, H. C., \& Van Gemert-Pijnen, J. E. W. C. (2012). Persuasive system design does matter: a systematic review of adherence to web-based interventions. Journal of Medical Internet Research, 14(6), e152. http://doi.org/10.2196/jmir.2104

Kelders, S. M., Pots, W. T., Oskam, M. J., Bohlmeijer, E. T., \& Van Gemert-Pijnen, J. E. (2013). Development of a web-based intervention for the indicated prevention of depression. BMC Medical Informatics and Decision Making, 13(1), 26. http://doi.org/10.1186/1472-6947-1326

Kessler, R. C., Berglund, P., Demler, O., Jin, R., Koretz, D., Merikangas, K. R., et al. (2003). The Epidemiology of Major Depressive Disorder: Results From the National Comorbidity Survey Replication (NCS-R). Journal of the American Medical Association, 289(23), 3095-3105. http://doi.org/10.1001/jama.289.23.3095

Kessler, R. C., Berglund, P., Demler, O., Jin, R., Merikangas, K. R., \& Walters, E. E. (2005a). Lifetime Prevalence and Age-of-Onset Distributions of DSM-IV Disorders in the National Comorbidity Survey Replication. Archives of General Psychiatry, 62(6), 593-602. $\mathrm{http}: / /$ doi.org/10.1001/archpsyc.62.6.593

Kessler, R. C., Chiu, W. T., Demler, O., Merikangas, K. R., \& Walters, E. E. (2005b). Prevalence, severity, and comorbidity of 12-month DSM-IV disorders in the National Comorbidity Survey Replication. Archives of 
General Psychiatry, 62(6), 617-627.

http://doi.org/10.1001/archpsyc.62.6.617

Kessler, R. C., Merikangas, K. R., \& Wang, P. S. (2007). Prevalence, comorbidity, and service utilization for mood disorders in the United States at the beginning of the twenty-first century. Annual Review of Clinical Psychology, 3(1), 137-158.

http://doi.org/10.1146/annurev.clinpsy.3.022806.091444

Kiropoulos, L. A., Klein, B., Austin, D. W., Gilson, K., Pier, C., Mitchell, J., \& Ciechomski, L. (2008). Is internet-based CBT for panic disorder and agoraphobia as effective as face-to-face CBT? Journal of Anxiety Disorders, 22(8), 1273-1284.

http://doi.org/10.1016/j.janxdis.2008.01.008

Kivi, M., Eriksson, M. C. M., Hange, D., Petersson, E.-L., Vernmark, K., Johansson, B., \& Björkelund, C. (2014). Internet-based therapy for mild to moderate depression in Swedish primary care: short term results from the PRIM-NET randomized controlled trial. Cognitive Behaviour Therapy, 43(4), 289-298. http://doi.org/10.1080/16506073.2014.921834

Kleiboer, A., Smit, J., Bosmans, J., Ruwaard, J., Andersson, G., Topooco, N., et al. (2016). European COMPARative Effectiveness research on blended Depression treatment versus treatment-as-usual (ECOMPARED): study protocol for a randomized controlled, noninferiority trial in eight European countries. Trials, 17(1), 387. http://doi.org/10.1186/s13063-016-1511-1

Klein, D. N., Schwartz, J. E., Santiago, N. J., Vivian, D., Vocisano, C., Castonguay, L. G., et al. (2003). Therapeutic alliance in depression treatment: controlling for prior change and patient characteristics. Journal of Consulting and Clinical Psychology, 71(6), 997-1006. http://doi.org/10.1037/0022-006X.71.6.997

Knaevelsrud, C., \& Maercker, A. (2006). Does the quality of the working alliance predict treatment outcome in online psychotherapy for traumatized patients? Journal of Medical Internet Research, 8(4), e31. http://doi.org/10.2196/jmir.8.4.e31

Knaevelsrud, C., \& Maercker, A. (2007). Internet-based treatment for PTSD reduces distress and facilitates the development of a strong therapeutic alliance: a randomized controlled clinical trial. BMC Psychiatry, 7(1), 13. http://doi.org/10.1186/1471-244X-7-13

Kolovos, S., Kleiboer, A., \& Cuijpers, P. (2016). Effect of psychotherapy for depression on quality of life: meta-analysis. British Journal of Psychiatry, 209(6), 460-468. http://doi.org/10.1192/bjp.bp.115.175059 Kooistra, L. C., Ruwaard, J., Wiersma, J. E., Van Oppen, P., van der Vaart, R., Van Gemert-Pijnen, J. E. W. C., \& Riper, H. (2016). Development 
and initial evaluation of blended cognitive behavioural treatment for major depression in routine specialized mental health care. Internet Interventions, 4, 61-71. http://doi.org/10.1016/j.invent.2016.01.003

Kroenke, K., Spitzer, R. L., \& Williams, J. B. W. (2001). The PHQ-9: validity of a brief depression severity measure. Journal of General Internal Medicine, 16(9), 606-613. http://doi.org/10.1046/j.15251497.2001.016009606.x

Lappalainen, P., Granlund, A., Siltanen, S., Ahonen, S., Vitikainen, M., Tolvanen, A., \& Lappalainen, R. (2014). ACT Internet-based vs face-toface? A randomized controlled trial of two ways to deliver Acceptance and Commitment Therapy for depressive symptoms: an 18-month follow-up. Behaviour Research and Therapy, 61, 43-54. http://doi.org/10.1016/j.brat.2014.07.006

Lewinsohn, P., Muñoz, R. F., Youngren, M. A., \& Zeiss, A. M. (1986). Control Your Depression. New York: Simon and Schuster.

Lindhiem, O., Bennett, C. B., Rosen, D., \& Silk, J. (2015). Mobile Technology Boosts the Effectiveness of Psychotherapy and Behavioral Interventions. Behavior Modification, 39(6), 785-804. http://doi.org/10.1177/0145445515595198

Lindner, P., Nyström, M. B. T., Hassmén, P., Andersson, G., \& Carlbring, P. (2015). Who seeks ICBT for depression and how do they get there? Effects of recruitment source on patient demographics and clinical characteristics. Internet Interventions, 2(2), 221-225. http://doi.org/10.1016/j.invent.2015.04.002

Lindner, P., Olsson, E. L., Johnsson, A., Dahlin, M., Andersson, G., \& Carlbring, P. (2014). The impact of telephone versus e-mail therapist guidance on treatment outcomes, therapeutic alliance and treatment engagement in Internet-delivered CBT for depression: A randomised pilot trial. Internet Interventions, 1(4), 182-187. http://doi.org/10.1016/j.invent.2014.09.001

Ljótsson, B., Hedman, E., Andersson, E., Hesser, H., Lindfors, P., Hursti, T., et al. (2011). Internet-delivered exposure-based treatment vs. stress management for irritable bowel syndrome: a randomized trial. The American Journal of Gastroenterology, 106(8), 1481-1491. http://doi.org/10.1038/ajg.2011.139

Ly, K. H., Topooco, N., Cederlund, H., Wallin, A., Bergström, J., Molander, O., et al. (2015). Smartphone-supported versus full behavioural activation for depression: a randomised controlled trial. PLOS ONE, 10(5), e0126559. http://doi.org/10.1371/journal.pone.0126559

MacLeod, A., Rose, G., \& Williams, M. (1993). Components of Hopelessness About the Future in Parasuicide. Cognitive Therapy and 
Research, 17(5), 441-455.

Mahoney, A. E. J., Mackenzie, A., Williams, A. D., Smith, J., \& Andrews, G. (2014). Internet cognitive behavioural treatment for obsessive compulsive disorder: A randomised controlled trial. Behaviour Research and Therapy, 63, 99-106. http://doi.org/10.1016/j.brat.2014.09.012

Mallinckrodt, B., \& Tekie, Y. T. (2016). Item response theory analysis of Working Alliance Inventory, revised response format, and new Brief Alliance Inventory. Psychotherapy Research : Journal of the Society for Psychotherapy Research, 26(6), 694-718. http://doi.org/10.1080/10503307.2015.1061718

Marks, I. M., Cavanagh, K., \& Gega, L. (2007). Hands-on Help: computer aided psychotherapy. Maudsley Monographs, 49. New York: Psychology Press.

Martell, C. R., Addis, M. E., \& Jacobson, N. S. (2001). Depression in context: strategies for guided action. New York: W. W. Norton.

Martin, D. J., Garske, J. P., \& Katherine Davis, M. (2000). Relation of the therapeutic alliance with outcome and other variables: A meta-analytic review. Journal of Consulting and Clinical Psychology, 68(3), 438-450. http://doi.org/10.1037//0022-006X.68.3.438

Månsson, K. N. T., Skagius Ruiz, E., Gervind, E., Dahlin, M., \& Andersson, G. (2013). Development and initial evaluation of an Internet-based support system for face-to-face cognitive behavior therapy: a proof of concept study. Journal of Medical Internet Research, 15(12), e280. http://doi.org/10.2196/jmir.3031

McNaughton, J. (2016). Attachment Style, Therapeutic Alliance and Recovery in forensic mental health: the A-STAR study and clinical research portfolio (Doctoral dissertation, University of Glasgow)

Meldrum, M. L. (2000). A brief history of the randomized controlled trial. From oranges and lemons to the gold standard. Hematology/Oncology Clinics of North America, 14(4), 745-60- vii.

Mewton, L., Smith, J., Rossouw, P., \& Andrews, G. (2014). Current perspectives on Internet-delivered cognitive behavioral therapy for adults with anxiety and related disorders. Psychology Research and Behavior Management, 7, 37-46. http://doi.org/10.2147/PRBM.S40879

Meyer, T. J., Miller, M. L., Metzger, R. L., \& Borkovec, T. D. (1990). Development and validation of the Penn State Worry Questionnaire. Behaviour Research and Therapy, 28(6), 487-495.

Mohr, D. C., Cuijpers, P., \& Lehman, K. (2011). Supportive accountability: a model for providing human support to enhance adherence to eHealth interventions. Journal of Medical Internet Research, 13(1), e30. http://doi.org/10.2196/jmir.1602 
Munder, T. (2007). Die deutschsprachige Kurzversion des Working Alliance Inventory. Unpublished master's thesis, University of Freiburg, Germany. [The German short version of the Working Alliance Inventory].

Munder, T., Wilmers, F., Leonhart, R., Linster, H. W., \& Barth, J. (2010). Working Alliance Inventory-Short Revised (WAI-SR): psychometric properties in outpatients and inpatients. Clinical Psychology \& Psychotherapy, 17(3), 231-239. http://doi.org/10.1002/cpp.658

Murray, C. J. L., Vos, T., Lozano, R., Naghavi, M., Flaxman, A. D., Michaud, C., et al. (2012). Disability-adjusted life years (DALYs) for 291 diseases and injuries in 21 regions, 1990-2010: a systematic analysis for the Global Burden of Disease Study 2010. The Lancet, 380(9859), 2197-2223. http://doi.org/10.1016/S0140-6736(12)61689-4

Nasiakos, G., Cribbie, R. A., \& Arpin-Cribbie, C. A. (2010). Equivalencebased measures of clinical significance: assessing treatments for depression. Psychotherapy Research : Journal of the Society for Psychotherapy Research, 20(6), 647-656. http://doi.org/10.1080/10503307.2010.501039

Nyström, M. B. T., Neely, G., Hassmén, P., \& Carlbring, P. (2015). Treating Major Depression with Physical Activity: A Systematic Overview with Recommendations. Cognitive Behaviour Therapy, 44(4), 341-352. http://doi.org/10.1080/16506073.2015.1015440

Pagnin, D., de Queiroz, V., Pini, S., \& Cassano, G. B. (2004). Efficacy of ECT in depression: a meta-analytic review. The Journal of ECT, 20(1), 13-20.

Paxling, B., Almlöv, J., Dahlin, M., Carlbring, P., Breitholtz, E., Eriksson, T., \& Andersson, G. (2011). Guided internet-delivered cognitive behavior therapy for generalized anxiety disorder: a randomized controlled trial. Cognitive Behaviour Therapy, 40(3), 159-173. http://doi.org/10.1080/16506073.2011.576699

Paxling, B., Lundgren, S., Norman, A., Almlöv, J., Carlbring, P., Cuijpers, P., \& Andersson, G. (2013). Therapist behaviours in internet-delivered cognitive behaviour therapy: analyses of e-mail correspondence in the treatment of generalized anxiety disorder. Behavioural and Cognitive Psychotherapy, 41(3), 280-289. http://doi.org/10.1017/S1352465812000240

Preschl, B., Maercker, A., \& Wagner, B. (2011). The working alliance in a randomized controlled trial comparing online with face-to-face cognitive-behavioral therapy for depression. BMC Psychiatry, 11(1), 189. http://doi.org/10.1186/1471-244X-11-189

Proudfoot, J., Klein, B., Barak, A., Carlbring, P., Cuijpers, P., Lange, A., et 
al. (2011). Establishing guidelines for executing and reporting Internet intervention research. Cognitive Behaviour Therapy, 40(2), 82-97. http://doi.org/10.1080/16506073.2011.573807

Reynolds, D. J., Stiles, W. B., Bailer, A. J., \& Hughes, M. R. (2013). Impact of exchanges and client-therapist alliance in online-text psychotherapy. Cyberpsychology, Behavior and Social Networking, 16(5), 370-377. http://doi.org/10.1089/cyber.2012.0195

Richards, Derek, \& Richardson, T. (2012). Computer-based psychological treatments for depression: a systematic review and meta-analysis.

Clinical Psychology Review, 32(4), 329-342. http://doi.org/10.1016/j.cpr.2012.02.004

Richardson, R., Richards, D., \& Barkham, M. (2010). Self-help books for people with depression: the role of the therapeutic relationship. Behavioural and Cognitive Psychotherapy, 38(1), 67-81. http://doi.org/10.1017/S1352465809990452

Rodríguez-Testal, J. F., Senín-Calderón, C., \& Perona-Garcelán, S. (2014). From DSM-IV-TR to DSM-5: Analysis of some changes. International Journal of Clinical and Health Psychology, 14(3), 221-231. http://doi.org/10.1016/j.ijchp.2014.05.002

Rush, A. J., Beck, A. T., Kovacs, M., \& Hollon, S. (1977). Comparative efficacy of cognitive therapy and pharmacotherapy in the treatment of depressed outpatients. Cognitive Therapy and Research, 1(1), 17-37. http://doi.org/10.1007/BF01173502

Rutherford, B. R., Mori, S., Sneed, J. R., Pimontel, M. A., \& Roose, S. P. (2012). Contribution of spontaneous improvement to placebo response in depression: a meta-analytic review. Journal of Psychiatric Research, 46(6), 697-702. http://doi.org/10.1016/j.jpsychires.2012.02.008

Ruwaard, J., Lange, A., Schrieken, B., Dolan, C. V., \& Emmelkamp, P. (2012). The effectiveness of online cognitive behavioral treatment in routine clinical practice. PLoS ONE, 7(7), e40089. http://doi.org/10.1371/journal.pone.0040089

Ruwaard, J., Schrieken, B., Schrijver, M., Broeksteeg, J., Dekker, J., Vermeulen, H., \& Lange, A. (2009). Standardized web-based cognitive behavioural therapy of mild to moderate depression: a randomized controlled trial with a long-term follow-up. Cognitive Behaviour Therapy, 38(4), 206-221. http://doi.org/10.1080/16506070802408086

Saddichha, S., Al-Desouki, M., Lamia, A., Linden, I. A., \& Krausz, M. (2014). Online interventions for depression and anxiety - a systematic review. Health Psychology and Behavioral Medicine, 2(1), 841-881. http://doi.org/10.1080/21642850.2014.945934

Saito, M., Iwata, N., Kawakami, N., Matsuyama, Y., World Mental Health Japan 2002-2003 Collaborators, Ono, Y., et al. (2010). Evaluation of 
the DSM-IV and ICD-10 criteria for depressive disorders in a community population in Japan using item response theory.

International Journal of Methods in Psychiatric Research, 19(4), 211222. http://doi.org/10.1002/mpr.320

Saragoussi, D., Touya, M., Haro, J. M., Jönsson, B., Knapp, M., Botrel, B., et al. (2017). Factors associated with failure to achieve remission and with relapse after remission in patients with major depressive disorder in the PERFORM study. Neuropsychiatric Disease and Treatment, 13, 2151-2165. http://doi.org/10.2147/NDT.S136343

Sarkohi, A., Bjärehed, J., \& Andersson, G. (2011). Links between future thinking and autobiographical memory specificity in major depression. Psychology, 02(03), 261-265. http://doi.org/10.4236/psych.2011.23041

Statens beredning för medicinsk utvärdering. (2012). Diagnostik och uppföljning av förstämningssyndrom: en systematisk litteraturöversikt (SBU-rapport 212). Stockholm: Statens beredning för medicinsk utvärdering (SBU)

Schneider, L. H., Hadjistavropoulos, H. D., \& Faller, Y. N. (2016). Internetdelivered cognitive behaviour therapy for depressive symptoms: an exploratory examination of therapist behaviours and their relationship to outcome and therapeutic alliance. Behavioural and Cognitive Psychotherapy, 44(6), 625-639. http://doi.org/10.1017/S1352465816000254

Scogin, F., Jamison, C., \& Davis, N. (1990). Two-year follow-up of bibliotherapy for depression in older adults. Journal of Consulting and Clinical Psychology, 58(5), 665-667. http://doi.org/10.1037/0022006X.58.5.665

Sheehan, D. V., Lecrubier, Y., Sheehan, K. H., Amorim, P., Janavs, J., Weiller, E., et al. (1998). The Mini-International Neuropsychiatric Interview (M.I.N.I.): the development and validation of a structured diagnostic psychiatric interview for DSM-IV and ICD-10. The Journal of Clinical Psychiatry, 59 Suppl 20, 22-33-quiz 34-57.

Short, C. E., Rebar, A. L., \& Plotnikoff, R. C. (2015). Designing engaging online behaviour change interventions: A proposed model of user engagement. The European Health Psychologist, 17(1), 32-38.

Sobocki, P., Lekander, I., Borgström, F., Ström, O., \& Runeson, B. (2007). The economic burden of depression in Sweden from 1997 to 2005. European Psychiatry, 22(3), 146-152. http://doi.org/10.1016/j.eurpsy.2006.10.006

Socialstyrelsen. (2016). Nationella riktlinjer för vård vid depression och ångestsyndrom: stöd för styrning och ledning (remissversion). Stockholm:

Spek, V., Cuijpers, P., Nyklíček, I., Riper, H., Keyzer, J., \& Pop, V. (2007). 
Internet-based cognitive behaviour therapy for symptoms of depression and anxiety: a meta-analysis. Psychological Medicine, 37(3), 319-328. http://doi.org/10.1017/S0033291706008944

Steketee, G., \& Chambless, D. L. (1992). Methodological issues in prediction of treatment outcome. Clinical Psychology Review, 12(4), 387-400. http://doi.org/10.1016/0272-7358(92)90123-P

Stiles-Shields, C., Kwasny, M. J., Cai, X., \& Mohr, D. C. (2014). Therapeutic alliance in face-to-face and telephone-administered cognitive behavioral therapy. Journal of Consulting and Clinical Psychology, 82(2), 349-354. http://doi.org/10.1037/a0035554

Ström, L., Pettersson, R., \& Andersson, G. (2004). Internet-based treatment for insomnia: a controlled evaluation. Journal of Consulting and Clinical Psychology, 72(1), 113-120. http://doi.org/10.1037/0022006X.72.1.113

Sucala, M., Schnur, J. B., Constantino, M. J., Miller, S. J., Brackman, E. H., \& Montgomery, G. H. (2012). The therapeutic relationship in e-therapy for mental health: a systematic review. Journal of Medical Internet Research, 14(4), e110-13. http://doi.org/10.2196/jmir.2084

Svanborg, P., \& Åsberg, M. (1994). A new self-rating scale for depression and anxiety states based on the Comprehensive Psychopathological Rating Scale. Acta Psychiatrica Scandinavica, 89(1), 21-28.

Svanborg, P., \& Åsberg, M. (2001). A comparison between the Beck Depression Inventory (BDI) and the self-rating version of the Montgomery Åsberg Depression Rating Scale (MADRS). Journal of Affective Disorders, 64(2-3), 203-216. http://doi.org/10.1016/S01650327(00)00242-1

Svartvatten, N., Segerlund, M., Dennhag, I., Andersson, G., \& Carlbring, P. (2015). A content analysis of client e-mails in guided internet-based cognitive behavior therapy for depression. Internet Interventions, 2(2), 121-127.

Thase, M. E., Wright, J. H., Eells, T. D., Barrett, M. S., Wisniewski, S. R., Balasubramani, G. K., et al. (2017). Improving the efficiency of psychotherapy for depression: computer-assisted versus standard CBT. The American Journal of Psychiatry, appiajp201717010089. http://doi.org/10.1176/appi.ajp.2017.17010089

Titov, N., Andrews, G., Davies, M., McIntyre, K., Robinson, E., \& Solley, K. (2010). Internet treatment for depression: a randomized controlled trial comparing clinician vs. technician assistance. PLoS ONE, 5(6), e10939. http://doi.org/10.1371/journal.pone.0010939

Titov, N., Andrews, G., Robinson, E., Schwencke, G., Johnston, L., Solley, K., \& Choi, I. (2009). Clinician-assisted Internet-based treatment is effective for generalized anxiety disorder: randomized controlled trial. 
Australian and New Zealand Journal of Psychiatry, 43(10), 905-912. http://doi.org/10.1080/00048670903179269

Titov, N., Dear, B. F., McMillan, D., Anderson, T., Zou, J., \& Sunderland, M. (2011). Psychometric comparison of the PHQ-9 and BDI-II for measuring response during treatment of depression. Cognitive Behaviour Therapy, 40(2), 126-136. http://doi.org/10.1080/16506073.2010.550059

Topooco, N., Riper, H., Araya, R., Berking, M., Brunn, M., Chevreul, K., et al. (2017). Attitudes towards digital treatment for depression: A European stakeholder survey. Internet Interventions, 8, 1-9. http://doi.org/10.1016/j.invent.2017.01.001

Tracey, T. J., \& Kokotovic, A. M. (1989). Factor Structure of the Working Alliance Inventory. Psychological Assessment, 1(3), 207-210.

Tryon, G. S., Blackwell, S. C., \& Hammel, E. F. (2007). A meta-analytic examination of client-therapist perspectives of the working alliance. Psychotherapy Research, 17(6), 629-642. http://doi.org/10.1080/10503300701320611

van Ballegooijen, W., Cuijpers, P., van Straten, A., Karyotaki, E., Andersson, G., Smit, J. H., \& Riper, H. (2014). Adherence to Internetbased and face-to-face cognitive behavioural therapy for depression: a meta-analysis. PLoS ONE, 9(7), e100674. http://doi.org/10.1371/journal.pone.0100674

Vlaescu, G., Alasjö, A., Miloff, A., Carlbring, P., \& Andersson, G. (2016). Features and functionality of the Iterapi platform for internet-based psychological treatment. Internet Interventions, 6, 107-114. http://doi.org/10.1016/j.invent.2016.09.006

Waller, G. (2009). Evidence-based treatment and therapist drift. Behaviour Research and Therapy, 47(2), 119-127. http://doi.org/10.1016/j.brat.2008.10.018

Wampold, B. E. (2015). How important are the common factors in psychotherapy? An update. World Psychiatry, 14(3), 270-277. http://doi.org/10.1002/wps.20238

Warmerdam, L., van Straten, A., Twisk, J., \& Cuijpers, P. (2013). Predicting outcome of Internet-based treatment for depressive symptoms. Psychotherapy Research, 23(5), 559-567. http://doi.org/10.1080/10503307.2013.807377

Watkins, E., Newbold, A., Tester-Jones, M., Javaid, M., Cadman, J., Collins, L. M., et al. (2016). Implementing multifactorial psychotherapy research in online virtual environments (IMPROVE-2): Study protocol for a phase III trial of the MOST randomized component selection method for internet cognitive-behavioural therapy for depression. $B M C$ Psychiatry, 16(1), 27. http://doi.org/10.1186/s12888-016-1054-8 
Watts, S., Mackenzie, A., Thomas, C., Griskaitis, A., Mewton, L., Williams, A., \& Andrews, G. (2013). CBT for depression: A pilot RCT comparing mobile phone vs. computer. BMC Psychiatry, 13(1), 49.

http://doi.org/10.1186/1471-244X-13-49

Webb, C. A., Beard, C., Auerbach, R. P., Menninger, E., \& Björgvinsson, T. (2014). The therapeutic alliance in a naturalistic psychiatric setting:

Temporal relations with depressive symptom change. Behaviour Research and Therapy, 61, 70-77.

http://doi.org/10.1016/j.brat.2014.07.015

Webb, C. A., DeRubeis, R. J., Amsterdam, J. D., Shelton, R. C., Hollon, S. D., \& Dimidjian, S. (2011). Two aspects of the therapeutic alliance: Differential relations with depressive symptom change. Journal of Consulting and Clinical Psychology, 79(3), 279-283. http://doi.org/10.1037/a0023252

Weizenbaum, J. (1966). ELIZA - a computer program for the study of natural language communication between man and machine. Communications of the ACM, 9(1), 36-45.

Wentzel, J., van der Vaart, R., Bohlmeijer, E. T., \& Van Gemert-Pijnen, J. E. W. C. (2016). Mixing online and face-to-face therapy: how to benefit from blended care in mental health care. JMIR Mental Health, 3(1), e97. http://doi.org/10.2196/mental.4534

Wikberg, C., Nejati, S., Larsson, M. E. H., Petersson, E.-L., Westman, J., Ariai, N., et al. (2015). Comparison between the Montgomery-Asberg Depression Rating Scale-self and the Beck Depression Inventory II in primary care. The Primary Care Companion for CNS Disorders, 17(3). http://doi.org/10.4088/PCC.14m01758

Williams, M. J., \& Broadbent, K. (1986). Autobiographical memory in suicide attempters. Journal of Abnormal Psychology, 95(2), 144-149.

World Health Organization. (1992). The ICD-10 Classification of Mental and Behavioural Disorders. World Health Organization.

Wright, J. H., Wright, A. S., Albano, A. M., Basco, M. R., Goldsmith, L. J., Raffield, T., \& Otto, M. W. (2005). Computer-Assisted Cognitive Therapy for Depression: Maintaining Efficacy While Reducing Therapist Time. American Journal of Psychiatry, 162(6), 1158-1164. http://doi.org/10.1176/appi.ajp.162.6.1158

Xu, H., \& Tracey, T. J. G. (2015). Reciprocal influence model of working alliance and therapeutic outcome over individual therapy course. Journal of Counseling Psychology, 62(3), 351-359. http://doi.org/10.1037/cou0000089

Zetterqvist, K., Maanmies, J., Ström, L., \& Andersson, G. (2003). Randomized controlled trial of internet-based stress management. Cognitive Behaviour Therapy, 32(3), 151-160. 


\section{Papers}

The papers associated with this thesis have been removed for copyright reasons. For more details about these see:

http:// urn.kb.se/ resolve?urn=urn:nbn:se:liu:diva-142389 